\title{
RNA-Mediated Control in Listeria monocytogenes: Insights Into Regulatory Mechanisms and Roles in Metabolism and Virulence
}

\section{OPEN ACCESS}

Edited by:

Olga Soutourina,

UMR 9198 Institut de Biologie

Intégrative de la Cellule (I2BC), France

Reviewed by:

Svetlana Chabelskaya,

Institut National de la Santé et de la

Recherche Médicale (INSERM),

France

Soraya Chaturongakul,

Mahidol University, Thailand

${ }^{*}$ Correspondence:

Agata Krawczyk-Balska

akra@biol.uw.edu.pl

Specialty section:

This article was submitted to Microbial Physiology and Metabolism,

a section of the journal

Frontiers in Microbiology

Received: 29 October 2020

Accepted: 16 March 2021

Published: 14 April 2021

Citation:

Krawczyk-Balska A, Ładziak M,

Burmistrz M, Ścibek K and Kallipolitis BH (2021) RNA-Mediated

Control in Listeria monocytogenes: Insights Into Regulatory Mechanisms and Roles in Metabolism and Virulence.

Front. Microbiol. 12:622829. doi: 10.3389/fmicb.2021.622829

\author{
Agata Krawczyk-Balska ${ }^{1 *}$, Magdalena Ładziak' ${ }^{1}$,Michał Burmistrz ${ }^{1}$, Katarzyna Ścibek $^{1}$ \\ and Birgitte H. Kallipolitis ${ }^{2}$
}

' Department of Molecular Microbiology, Biological and Chemical Research Centre, Faculty of Biology, University of Warsaw, Warsaw, Poland, ${ }^{2}$ Department of Biochemistry and Molecular Biology, University of Southern Denmark, Odense, Denmark

Listeria monocytogenes is an intracellular pathogen that is well known for its adaptability to life in a broad spectrum of different niches. RNA-mediated regulatory mechanisms in L. monocytogenes play important roles in successful adaptation providing fast and versatile responses to a changing environment. Recent findings indicate that noncoding RNAs (ncRNAs) regulate a variety of processes in this bacterium, such as environmental sensing, metabolism and virulence, as well as immune responses in eukaryotic cells. In this review, the current knowledge on RNA-mediated regulation in L. monocytogenes is presented, with special focus on the roles and mechanisms underlying modulation of metabolism and virulence. Collectively, these findings point to ncRNAs as important gene regulatory elements in L. monocytogenes, both outside and inside an infected host. However, the involvement of regulatory ncRNAs in bacterial physiology and virulence is still underestimated and probably will be better assessed in the coming years, especially in relation to discovering the regulatory functions of $5^{\prime}$ and $3^{\prime}$ untranslated regions and excludons, and by exploring the role of ncRNAs in interaction with both bacterial and host proteins.

Keywords: non-coding RNAs, post-transcriptional regulation, metabolism, virulence, Listeria monocytogenes

\section{INTRODUCTION}

Listeria monocytogenes is an intracellular, Gram-positive pathogen, responsible for foodborne infections called listerioses in humans and different animal species. This bacterium is well known for its adaptability to life in a broad spectrum of different niches, ranging from soil or wastewater to the cytoplasm of infected mammalian cells. L. monocytogenes is widely distributed in the environment owing to its ability to survive in different stress conditions, including $\mathrm{pH}$ variations, low temperature and high salt concentration (Ferreira et al., 2014). Infection with L. monocytogenes starts with the ingestion of contaminated food. In the intestine, L. monocytogenes invades epithelial cells as a result of the interaction of bacterial surface proteins with appropriate eukaryotic receptors. After crossing the intestinal barrier, L. monocytogenes enters into macrophage cells and is transported via blood to the liver and spleen. When the host's cell-mediated response is impaired, L. monocytogenes multiplies in these organs and subsequently spreads through the blood to different 
organs, often crossing placental and blood-brain barriers, leading to septicemia, meningitis and miscarriage in the case of pregnant women (McLauchlin et al., 2004; Liu et al., 2007). L. monocytogenes has the ability to invade the host's cells, multiply inside them and spread from cell to cell owing to tightly regulated expression of genes encoding virulence factors (Cossart, 2011).

The regulation of gene expression has a pivotal role in the virulence of L. monocytogenes and the ability of this bacterium to survive in different stress conditions. Proper changes in gene expression programs are indispensable in allowing saprophytic growth, stress response and resistance to extreme conditions, or triggering virulence properties. Numerous studies have documented the importance of protein regulators in the coordination of the infection process. The master coordinator of transcription of the virulence genes of L. monocytogenes is transcriptional regulator PrfA (positive regulatory factor A), which belongs to the superfamily of cyclic AMP receptor proteins (Crp) (Renzoni et al., 1999; Reniere et al., 2016). Other regulators of expression of virulence and virulence-associated genes are the alternative sigma factor Sigma B (Dorey et al., 2019), twocomponent signal transduction systems CesRK, LisRK, and VirRS, as well as the nutrient-responsive regulator CodY (Cotter et al., 1999; Kallipolitis et al., 2003; Mandin et al., 2005; Lobel et al., 2015). While knowledge about protein-mediated control of L. monocytogenes gene expression to environmental changes has been acquired over many decades, recent studies have shown that pathogenesis and stress adaptation of this bacterium are also regulated post-transcriptionally by ncRNA molecules. Generally, ncRNAs can be divided into five main categories. The first category contains small regulatory RNAs encoded in trans relative to the genes they regulate (trans ncRNAs). Some trans ncRNAs mainly act through interactions with proteins, whereas others control gene expression through base pairing with RNA transcripts (Storz et al., 2011). The base pairing trans ncRNAs affect the translation and/or stability of mRNAs originating from different sites in the genome. They show incomplete complementarity with their targets and thus can interact with multiple mRNAs. The interaction of trans ncRNAs with target mRNAs in bacteria is often mediated by the RNA chaperone Hfq (Christiansen et al., 2006). The second category contains cis-acting regulatory RNAs encoded from the $5^{\prime}$ regions of the genes they regulate (cis ncRNAs). They fold into two alternative RNA structures that terminate or antiterminate transcription of downstream genes. The rearrangements of cis ncRNA structures are coupled with translation of small ORFs within their sequences. The third category comprises antisense RNAs (asRNAs), including long antisense RNAs (lasRNAs). These molecules are encoded on the opposite strand relative to the genes they regulate, which makes them perfectly complementary to the target mRNA. Hybridization of asRNAs to target mRNAs often affects their stability and/or translational activity (Waters and Storz, 2009; Wurtzel et al., 2012). The recently discovered excludon corresponds to a genomic locus encoding a lasRNA (Wurtzel et al., 2012). The transcription of an excludon inhibits expression of the gene encoded on the opposite strand and also ensures expression of the downstream operon. The fourth category, viewed by some as the simplest form of RNA regulatory elements, are cis-encoded and cis-acting molecules, which undergo conformational changes upon binding a specific ligand (riboswitches) or in response to temperature change (thermosensors). Bacterial riboswitches and thermosensors are located mainly in the $5^{\prime}$ untranslated regions (UTRs) and less frequently in the $3^{\prime}$ UTRs of the genes that they control (Waters and Storz, 2009). Conformational changes in riboswitches and thermosensors located in $5^{\prime}$ UTR regions lead to premature transcription termination, arrest of translation initiation or both (Waters and Storz, 2009). Finally, the fifth category is comprised of $5^{\prime}$ and $3^{\prime}$ UTRs, whose regulatory mechanism relies on base pairing with other RNA transcripts.

While this general classification of ncRNAs is widely accepted and very useful due to its simplicity, mounting evidence suggests that ncRNAs are versatile regulators which can act by more than just a single mechanism as will be shown in this review.

Research devoted sensu stricto to riboregulation in L. monocytogenes began in 2002. At that time, it was discovered that the $5^{\prime}$ UTR of $\operatorname{prfA}$ switches between a structure active at high temperatures and inactive at low ones. This mechanism is driven by a thermosensor, which regulates the expression of $\operatorname{prf} A$, thereby controlling the virulence properties of L. monocytogenes (Johansson et al., 2002). Over the next several years, other ncRNAs of L. monocytogenes were discovered. The first identified and characterized small ncRNAs of $L$. monocytogenes were LhrA, LhrB and LhrC1-5 interacting with chaperone Hfq (Christiansen et al., 2006). Shortly after, further ncRNAs, i.e., RliA, RliB, RliC, RliD, RliE, RliF, RliG, RliH, RliI, and SbrA were identified using classical methods of molecular biology and bioinformatics (Mandin et al., 2007; Nielsen et al., 2008). During this time, the SreA and SreB riboswitches, which can act as trans ncRNAs to inhibit translation of $\operatorname{prfA}$ mRNA, were also discovered (Loh et al., 2009). The biggest scientific breakthrough in the discovery of riboregulatory elements in L. monocytogenes took place in 2009, when Toledo-Arana and coworkers presented the first study of the whole transcriptome of this bacterium. From that moment on, an enormous number of new ncRNAs was discovered, and in a few cases, their function and mechanisms of action was revealed. In this research, genomic tilling arrays was applied to compare the whole transcriptome of L. monocytogenes during growth in different physiologically relevant conditions including infection-relevant ones, i.e., whole human blood and the intestinal lumen of mice. Investigation of the transcriptome changes allowed understanding of the switching of L. monocytogenes from saphrophytism to virulence. These studies led to the identification of 50 ncRNAs, of which 29 were novel ncRNAs with sizes from 77 to 534 nucleotides (nt), including seven asRNAs. Furthermore, comprehensive information about changes in the expression of ncRNAs in different conditions was provided (Toledo-Arana et al., 2009). In the same year another study was performed by Oliver and coworkers, who applied a high-throughput RNA sequencing method with Illumina Genome Analyzer. This study allowed the identification of $67 \mathrm{~L}$. monocytogenes ncRNAs expressed in stationary phase of growth, with 60 molecules being previously described (Oliver et al., 2009). Another NGS (next generation sequencing) method, i.e., 454 pyrosequencing was used by 
Mraheil et al. (2011), in which sequencing of small RNA (below $500 \mathrm{nt}$ ) isolated from bacteria growing inside infected macrophages was carried out. This study led to the identification of 150 ncRNAs, whereof almost half had not been previously described (Mraheil et al., 2011). In the following year, NGS was applied to compare the transcriptomes of pathogenic L. monocytogenes with non-pathogenic Listeria innocua under various growth conditions (Wurtzel et al., 2012). The results of this study revealed the presence of 113 ncRNAs and 70 asRNAs in L. monocytogenes, of which 33 ncRNAs and 53 asRNAs had not been previously identified. This research also led to the identification of new lasRNAs that can act as asRNAs and mRNAs. Such a dual function for a lasRNA transcript was first described in L. monocytogenes for the lasRNA regulating flagellum biosynthesis (Toledo-Arana et al., 2009). This type of lasRNA was named an excludon. Another study that used a high-throughput SOLiD sequencing platform led to the discovery of 172 as yet undescribed ncRNAs candidates isolated from intracellularly and extracellularly growing L. monocytogenes (Behrens et al., 2014). This method led to the identification of nine new asRNAs and additionally revealed that four asRNAs are potentially longer than previously thought and could form lasRNAs (Behrens et al., 2014). In another whole transcriptomic study of L. monocytogenes under intracellular and extracellular growth conditions, a semiconductor sequencing technology and bioinformatic analysis pipeline was applied to identify 741 putative ncRNAs in L. monocytogenes, 441 of which had never been described before. One of the newly identified lasRNAs was a very long transcript of about 5,400 nt, fully complementary to a region from $l m o 2677$ up to $l m o 2680$ and partially to $k d p B$ (Wehner et al., 2014). The described progress in the discovery of ncRNAs in L. monocytogenes is shown in Figure 1. Altogether, a huge number of candidates for riboregulatory elements in L. monocytogenes have been identified throughout the last decade, and their number has been increasing in line with the progress in sequencing technology. Although the number of potential regulatory RNAs identified varies in different works, it is assumed that L. monocytogenes possesses more than 55 riboswitches, 100 asRNAs and 150 putative trans and cis ncRNAs (Schultze et al., 2014; Lebreton and Cossart, 2017). However, in spite of the rapid increase in the number of newly identified regulatory RNAs, their function and mechanism of action is poorly understood. Interestingly, recent studies have shown that ncRNAs are secreted by L. monocytogenes into the cytoplasm of infected cells where they modulate the innate immune response through interaction with the RNA sensor RIG-I (Frantz et al., 2019). Therefore, these molecules besides being potent regulators of gene expression, could also play a role as virulence effectors of L. monocytogenes. Furthermore, except for the classic riboregulatory elements, recent research has revealed that canonical mRNA can also be involved in regulatory base-pairing interactions extending riboregulatory mechanisms in L. monocytogenes beyond non-coding elements (Ignatov et al., 2020; Peterson et al., 2020). In this review, we focus on

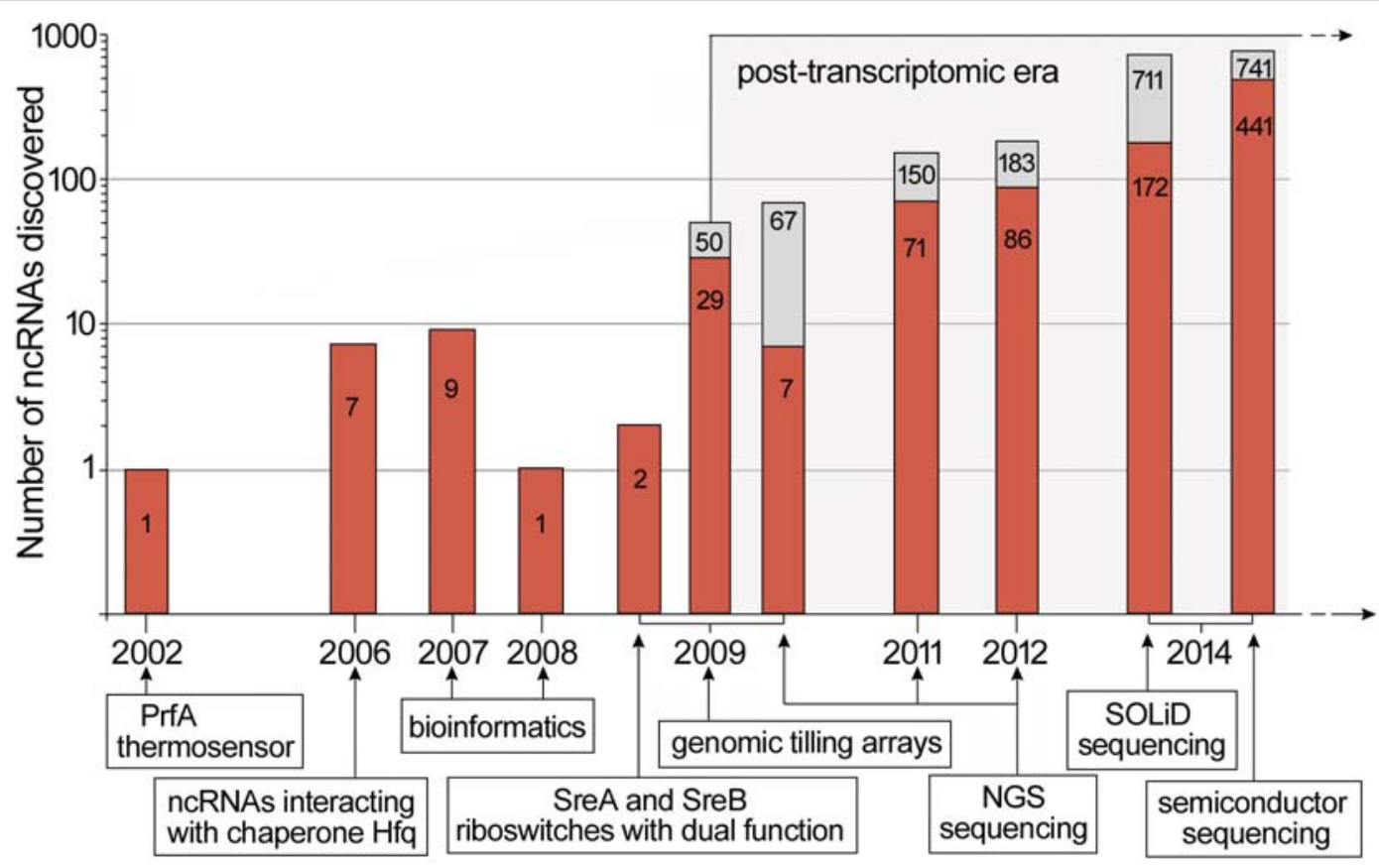

FIGURE 1 | Discovery timeline of ncRNAs in L. monocytogenes. New ncRNAs discovered are marked in red while the total number of ncRNAs discovered is indicated in gray. For high-throughput RNA analysis, the data represents putative riboregulatory candidates. Below the timeline, key scientific breakthroughs and novel methods applied in ncRNAs discovery are shown. The timeline is based on data presented in Johansson et al. (2002); Christiansen et al. (2006), Mandin et al. (2007); Nielsen et al. (2008), Loh et al. (2009); Oliver et al. (2009), Toledo-Arana et al. (2009); Mraheil et al. (2011), Wurtzel et al. (2012); Behrens et al. (2014), and Wehner et al. (2014). 
the riboregulators of $L$. monocytogenes which, besides being consistently identified in high-throughput studies, have been characterized in low-throughput analyses, providing summarized data on their physiological role and, when available, mechanism of action. The detailed characteristics of these riboregulators are presented in Table 1.

\section{TRANS REGULATORY ncRNAS}

\section{LhrA}

LhrA was identified as an ncRNA interacting with the chaperone Hfq of L. monocytogenes. The LhrA transcript is known to be present throughout the growth phase, reaching a maximum level at the onset of the stationary phase, which suggests a role for LhrA during transition from exponential to stationary phase of growth (Christiansen et al., 2006). Notably, the stability of LhrA is highly dependent on the presence of the Hfq chaperone (Christiansen et al., 2006). LhrA is highly conserved among Listeria species, and it seems to appear exclusively in the genus Listeria. In silico studies predicted the secondary structure of LhrA to contain four stem-loops and a well preserved single stranded, $21 \mathrm{nt}$ long motif, which is responsible for base pairing between this ncRNA and its targets. The first identified target for LhrA was 1 mo0850, which encodes a protein of unknown function. The regulation is dependent on Hfq, which facilitates base pairing between LhrA and a region upstream from the start codon of 1 mo0850 mRNA, leading to inhibition of translation followed by a decrease in mRNA stability (Nielsen et al., 2010). Further transcriptomic microarray-based studies showed that inactivation of $\operatorname{lhr} A$ influences the expression level of more than 300 genes in L. monocytogenes. Additionally, this study allowed for the identification of two other genes directly regulated by LhrA, i.e., Imo0302 and chiA, encoding a hypothetic protein and a chitinase, respectively. Similarly to regulation of lmo0850, these genes are downregulated by LhrA at the posttranscriptional level and the regulation is Hfq-dependent (Nielsen et al., 2011). So far, the dependency on Hfq for efficient binding of LhrA to its targets represents a unique example of Hfq chaperone involvement in ncRNA-mRNA interaction and posttranscriptional regulation in Gram-positive bacteria. A recent study revealed that transfection of eukaryotic cells with LhrA triggers moderate IFN- $\beta$ induction suggesting the involvement of LhrA in modulating the immune response during infection of the host organism (Frantz et al., 2019).

\section{LhrC Family (LhrC1-5, Rli33-1, and Rli22)}

The LhrC is a multicopy ncRNA family, which comprises seven homologous ncRNAs, ranging from 105 to $121 \mathrm{nt}$ in length. Notably, this ncRNA family holds the highest number of siblings reported so far. The first discovered members of this family were LhrC1-5 owing to their ability to interact with Hfq (Christiansen et al., 2006). LhrC1-5 arises from two different locations within the L. monocytogenes genome, i.e., lhrC1-4 located between genes cysK and sul, while $l$ hrC5 resides between $l m o 0946$ and lmo0947 (Table 1). Deletion of $1 \mathrm{hrC1}$-5 results in increased susceptibility of L. monocytogenes to the $\beta$-lactam antibiotic cefuroxime (Sievers et al., 2014), leads to decreased survival of L. monocytogenes in macrophage cells (Sievers et al., 2015), and impairs the adaptation of L. monocytogenes to excess of heme (dos Santos et al., 2018). While initially five LhrCs were discovered, further studies led to expanding the LhrC family to seven members based on the discovery of two additional ncRNAs, namely Rli22 and Rli33-1, that are structurally and functionally related to LhrC1-5, although they do not possess the ability to interact with the Hfq (Mollerup et al., 2016). Rli22 is encoded from the intergenic region of $1 m 00028$ and $l m o 0029$, and Rli33-1 was initially identified as part of a larger transcript, designated Rli33, encoded from the intergenic region of lmo0671 and $l$ mo0672 (Toledo-Arana et al., 2009). A more recent study identified two individual ncRNAs, Rli33-1 and Rli33-2, which suggests either the presence of an internal transcription start site (TSS) or an unknown RNA processing mechanism of Rli33 (Mraheil et al., 2011). Deletion of the rli33-1 gene resulted in decreased survival of $L$. monocytogenes in macrophage cells and led to attenuation of L. monocytogenes virulence in murine and insect models of infection (Mraheil et al., 2011). Despite their structural similarity, different LhrCs have expression patterns that vary to some extent from one another (Mollerup et al., 2016). Cell envelope stress was shown to induce the expression of LhrC1-5 and Rli22 via the LisRK two-component system. Rli331 expression is upregulated in response to osmotic stress and during stationary growth phase in a Sigma B-dependent manner. Rli22 was found to be upregulated in bacteria inside the intestinal lumen of mice (Toledo-Arana et al., 2009). On the contrary, Rli22 is the only representative of the LhrC family which is not upregulated during growth inside macrophages (Mraheil et al., 2011). All seven ncRNAs were shown to be expressed after exposure to blood (Toledo-Arana et al., 2009; Table 1).

To date, six targets for LhrCs have been identified. Five of these target genes encode surface proteins required for full virulence of L. monocytogenes. For three targets the mechanism of regulation has been studied in detail. The most important features and regulatory mechanisms of ncRNAs from the LhrC family are presented in Figure 2. The first target is $l a p B$ (lmo1666), which encodes a cell wall anchored adhesin. The second one is oppA (lmo2349) that encodes a substrate-binding protein of an oligopeptide transporter. The third target is tcsA (lmo1388), which encodes a CD4 $+\mathrm{T}$ cell-stimulating antigen. In two cases, the ncRNAs exert a negative effect on translation: for $l a p B$ and $o p p A$, the LhrCs are known to act by direct base pairing to the ribosome binding site (RBS), leading to inhibition of translation followed by mRNA degradation (Sievers et al., 2014, 2015) (see Figure 2A). In the case of $\operatorname{tcs} A$, the LhrC-binding site is located far upstream of the Shine-Dalgarno (SD) region in the $5^{\prime}$ UTR of the mRNA. Notably, the LhrCs act by promoting degradation of $\operatorname{tcs} A$ mRNA and do not affect the translation of this transcript (Sievers et al., 2015; Ross et al., 2019; Figure 2A). In addition to the three targets described above, the LhrCs are known to control the expression of genes involved in heme uptake and utilization: $\operatorname{lmo} 2186$ and $\operatorname{lmo} 2185$, encoding the heme-binding proteins $\mathrm{Hbp} 1$ and $\mathrm{Hbp} 2$, respectively, and 1 mo0484, encoding a heme oxygenase-like protein. Using in vitro binding assays, it was shown that the LhrCs interact with mRNAs encoded 
TABLE 1 | Characteristics of non-coding RNAs of L. monocytogenes.

\begin{tabular}{|c|c|c|c|c|c|c|}
\hline Name & Size (nt) & Genome & locus ${ }^{a}$ & $\begin{array}{l}\text { Conditions that induce } \uparrow \\
\text { or repress } \downarrow \text { expression }\end{array}$ & $\begin{array}{l}\text { Involvement in particular } \\
\text { processes/relevant comment }\end{array}$ & References \\
\hline \multicolumn{7}{|c|}{ Trans regulatory ncRNAs } \\
\hline LhrA & 268 & 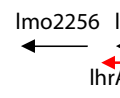 & $\stackrel{\operatorname{lmo} 2257}{\longleftarrow}$ & $\begin{array}{l}\text { Early stationary phase of } \\
\text { growth } \uparrow\end{array}$ & $\begin{array}{l}\text { Transition from log to stationary phase; } \\
\text { Chitinolytic activity; } \\
\text { Induction IFN- } \beta\end{array}$ & $\begin{array}{l}\text { Christiansen et al., 2006; } \\
\text { Nielsen et al., 2010, 2011; } \\
\text { Frantz et al., } 2019\end{array}$ \\
\hline LhrB & 140 & infC I & IhrB inlC & ND & $\mathrm{ND}$ & Christiansen et al., 2006 \\
\hline LhrC1-5 & $110-114$ & $\begin{array}{l}\stackrel{\text { cysK }}{\rightarrow} \stackrel{\operatorname{lhrC1}}{\longrightarrow} \\
\stackrel{\operatorname{Imo0946}}{\longrightarrow}\end{array}$ & 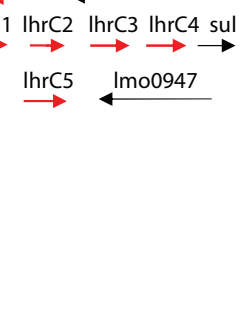 & $\begin{array}{l}\text { Cefuroxime } \uparrow \\
\text { High osmolarity } \uparrow \\
\text { Bile } \uparrow \\
\text { Acid } \uparrow \\
\text { Ethanol } \uparrow \\
\text { Blood } \uparrow \\
\text { Intracellular growth in } \\
\text { macrophages } \uparrow \\
\text { Hemin stress } \uparrow\end{array}$ & $\begin{array}{l}\text { Resistance to cefuroxime; } \\
\text { Virulence; } \\
\text { Heme toxicity }\end{array}$ & $\begin{array}{l}\text { Toledo-Arana et al., 2009; } \\
\text { Mraheil et al., 2011; } \\
\text { Sievers et al., 2014, 2015; } \\
\text { Mollerup et al., 2016; dos } \\
\text { Santos et al., 2018; Ross } \\
\text { et al., } 2019\end{array}$ \\
\hline $\begin{array}{l}\text { Rli33-1 } \\
\text { (LhrC6) }\end{array}$ & 121 & $\stackrel{\operatorname{lmo0671}}{\longrightarrow}$ & $\underset{\mathrm{rli33}}{\stackrel{\mathrm{rli33}-1}{\longrightarrow}} \stackrel{\mathrm{rli33}-2}{\longrightarrow} \stackrel{\operatorname{lmo0672}}{\longrightarrow}$ & $\begin{array}{l}\text { Intracellular growth in } \\
\text { macrophages } \uparrow \\
\text { Blood } \uparrow \\
\text { Stationary phase of growth } \uparrow \\
\text { High osmolarity } \uparrow\end{array}$ & Virulence & $\begin{array}{l}\text { Toledo-Arana et al., 2009; } \\
\text { Mraheil et al., 2011; } \\
\text { Mollerup et al., } 2016\end{array}$ \\
\hline $\begin{array}{l}\text { Rli22 } \\
\text { (LhrC7) }\end{array}$ & 105 & $\stackrel{\operatorname{Imo} 0028}{\longrightarrow}$ & $\stackrel{\mathrm{rli22}}{\longrightarrow} \stackrel{\operatorname{Imo0029}}{\longrightarrow}$ & $\begin{array}{l}\text { Intestinal lumen } \uparrow \\
\text { Blood } \uparrow \\
\text { Cefuroxime } \uparrow\end{array}$ & ND & $\begin{array}{l}\text { Toledo-Arana et al., 2009; } \\
\text { Mollerup et al., } 2016\end{array}$ \\
\hline RliB & 360 & $\stackrel{\mathrm{prs}}{\longrightarrow} \stackrel{\mathrm{r}}{\longrightarrow}$ & $\stackrel{\mathrm{rliB}}{\longrightarrow} \stackrel{\operatorname{Imo0510}}{\longrightarrow}$ & $\begin{array}{l}\text { Intestinal lumen } \uparrow \\
\text { Blood } \uparrow \\
\text { Low oxygen conditions } \uparrow\end{array}$ & $\begin{array}{l}\text { Virulence; } \\
\text { Related to CRISPR in a } \\
\text { PnpA-dependent manner }\end{array}$ & $\begin{array}{l}\text { Mandin et al., 2007; } \\
\text { Toledo-Arana et al., 2009; } \\
\text { Mraheil et al., 2011; Sesto } \\
\text { et al., } 2014\end{array}$ \\
\hline Rlie & 223 & $\stackrel{\mathrm{comC}}{\underset{\mathrm{rliE}}{\longrightarrow}}$ & $\rightarrow$ & ND & ND & Mandin et al., 2007 \\
\hline Rlil & 239 & $\operatorname{lmo} 2760$ & $\stackrel{\text { rlil }}{\longrightarrow} \stackrel{\operatorname{Imo} 2761}{\longrightarrow}$ & Stationary phase of growth $\uparrow$ & ND & $\begin{array}{l}\text { Mandin et al., 2007; Dar } \\
\text { et al., } 2016\end{array}$ \\
\hline SbrA & 70 & $\stackrel{\operatorname{lmo1374}}{\longrightarrow} \frac{\mathrm{sbr}}{\mathrm{mbr}}$ & 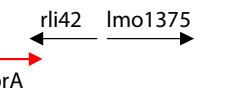 & $\begin{array}{l}\text { High osmolarity } \uparrow \\
\text { ethanol } \uparrow \\
\text { Stationary phase of growth } \uparrow\end{array}$ & ND & $\begin{array}{l}\text { Nielsen et al., 2008; } \\
\text { Toledo-Arana et al., } 2009\end{array}$ \\
\hline $\begin{array}{l}\text { SbrE } \\
(\text { Rli47) }\end{array}$ & 515 & $\stackrel{\operatorname{Imo} 2141}{\longrightarrow}$ & $\stackrel{\mathrm{sbrE}}{\longrightarrow} \stackrel{\operatorname{Imo} 2142}{\longleftarrow}$ & $\begin{array}{l}\text { Stationary phase of growth } \uparrow \\
\text { Intestinal lumen } \uparrow \\
\text { Intracellular growth in } \\
\text { macrophages } \uparrow \\
\text { Oxidative stress } \uparrow \\
\text { Growth with other bacteria } \uparrow\end{array}$ & $\begin{array}{l}\text { Inhibition of growth through repressing } \\
\text { isoleucine biosynthesis }\end{array}$ & $\begin{array}{l}\text { Oliver et al., 2009; } \\
\text { Toledo-Arana et al., 2009; } \\
\text { Mraheil et al., 2011; } \\
\text { Mujahid et al., 2012; } \\
\text { Marinho et al., 2019; Anast } \\
\text { and Schmitz-Esser, } 2020\end{array}$ \\
\hline Rli27 & 131 & 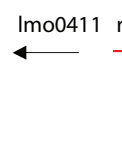 & $\stackrel{\text { rli27 }}{\longrightarrow} \stackrel{\operatorname{Imo} 0412}{\longleftarrow}$ & $\begin{array}{l}\text { Intestinal lumen } \uparrow \\
\text { Blood } \uparrow \\
\text { Intracellular growth in epithelial } \\
\text { cells } \uparrow\end{array}$ & Survival in blood plasma & $\begin{array}{l}\text { Toledo-Arana et al., 2009; } \\
\text { Quereda et al., 2014, } 2016\end{array}$ \\
\hline Rli31 & 144 & $\stackrel{\operatorname{lmo0558}}{\longleftarrow}$ & $\stackrel{\text { rli31 }}{\longrightarrow} \longrightarrow$ & $\begin{array}{l}\text { Intracellular growth in } \\
\text { macrophages } \uparrow\end{array}$ & $\begin{array}{l}\text { Virulence; } \\
\text { Lysozyme resistance }\end{array}$ & $\begin{array}{l}\text { Toledo-Arana et al., 2009; } \\
\text { Mraheil et al., 2011; Burke } \\
\text { et al., 2014; Dar et al., } \\
\text { 2016; Burke and Portnoy, } \\
2016\end{array}$ \\
\hline Rli32 & 147 & $\stackrel{\operatorname{lmo0560}}{\longleftarrow}$ & $\stackrel{\text { rli32 Imo0561 }}{\longleftarrow}$ & $\begin{array}{l}\text { Intracellular growth in } \\
\text { macrophages } \uparrow\end{array}$ & $\begin{array}{l}\text { Virulence; oxidative stress response; } \\
\text { resistance to cefuroxime; } \\
\text { Strong IFN- } \beta \text { induction }\end{array}$ & $\begin{array}{l}\text { Mraheil et al., 2011; Burke } \\
\text { et al., 2014; Grubaugh } \\
\text { et al., 2018; Frantz et al., } \\
2019\end{array}$ \\
\hline Rli38 & 369 & $\longleftarrow$ & $\stackrel{\text { rli38 }}{\longrightarrow} \stackrel{\operatorname{Imo1116}}{\longrightarrow}$ & $\begin{array}{l}\text { Stationary phase of growth } \uparrow \\
\text { Blood } \uparrow \\
\text { Oxidative stress } \uparrow\end{array}$ & Virulence & Toledo-Arana et al., 2009 \\
\hline Rli50 & 306 & $\stackrel{\operatorname{Imo} 2709}{\longleftarrow}$ & $\underset{\mathrm{rli50}}{\stackrel{\mathrm{rli112}}{\longrightarrow}} \stackrel{\operatorname{Imo} 2710}{\longleftarrow}$ & ND & $\begin{array}{l}\text { Virulence; } \\
\text { IFN- } \beta \text { induction }\end{array}$ & $\begin{array}{l}\text { Toledo-Arana et al., 2009; } \\
\text { Mraheil et al., 2011; Frantz } \\
\text { et al., } 2019\end{array}$ \\
\hline
\end{tabular}


TABLE 1 | Continued

\begin{tabular}{|c|c|c|c|c|c|}
\hline Name & Size (nt) & Genome locus $^{a}$ & $\begin{array}{l}\text { Conditions that induce } \uparrow \text { or } \\
\text { repress } \downarrow \text { expression }^{\text {b }}\end{array}$ & $\begin{array}{l}\text { Involvement in particular } \\
\text { processes/relevant comment }\end{array}$ & References \\
\hline \multicolumn{6}{|c|}{ Cis regulatory ncRNAs } \\
\hline Rli53 & 207 & $\stackrel{\text { Imo0918 }}{\longrightarrow} \stackrel{\text { rli53 }}{\longrightarrow} \stackrel{\text { Imo0919 }}{\longrightarrow}$ & $\begin{array}{l}\text { Intracellular growth in } \\
\text { macrophages } \uparrow\end{array}$ & Lincomycin resistance & $\begin{array}{l}\text { Toledo-Arana et al., 2009; } \\
\text { Mraheil et al., 2011; Dar } \\
\text { et al., } 2016\end{array}$ \\
\hline Rli59 & 214 & 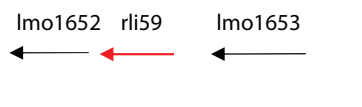 & $\begin{array}{l}\text { Intestinal lumen } \uparrow \text { blood } \uparrow \\
\text { Intracellular growth in } \\
\text { macrophages } \downarrow\end{array}$ & ND & $\begin{array}{l}\text { Toledo-Arana et al., 2009; } \\
\text { Dar et al., } 2016\end{array}$ \\
\hline Rli60 & 247 & $\stackrel{\text { Imo1982 }}{\longrightarrow} \stackrel{\text { rli60 }}{\longrightarrow} \stackrel{\text { ilvD }}{\longrightarrow}$ & Low BCAA concentration $\uparrow$ & $\begin{array}{l}\text { Control of BCAA biosynthesis; } \\
\text { virulence; stress adaptation; biofilm } \\
\text { formation; IFN- } \beta \text { induction }\end{array}$ & $\begin{array}{l}\text { Toledo-Arana et al., 2009; } \\
\text { Peng et al., 2016a,b; } \\
\text { Brenner et al., 2018; Frantz } \\
\text { et al., } 2019\end{array}$ \\
\hline \multicolumn{6}{|c|}{ lasRNA (excludon) } \\
\hline $\begin{array}{l}\text { Anti0677 } \\
\text { (excludon) }\end{array}$ & 2900 & $\underset{\text { anti0677 }}{\longrightarrow} \longrightarrow \longrightarrow$ & Stationary phase of growth $\uparrow$ & Control of motility & Toledo-Arana et al., 2009 \\
\hline \multicolumn{6}{|c|}{ Riboswitches and thermosensors } \\
\hline $\begin{array}{l}\text { PrfA } \\
\text { thermosensor }\end{array}$ & 127 & $\longleftarrow^{\text {prfA }}$ & $\begin{array}{l}37^{\circ} \mathrm{C} \uparrow \\
\text { infection } \uparrow\end{array}$ & Virulence & Johansson et al., 2002 \\
\hline $\begin{array}{l}\text { SAM riboswitcl } \\
\text { (SreA) }\end{array}$ & 1229 & $\operatorname{Imo} 2417 \operatorname{Imo} 2418 \operatorname{Imo} 2419$ & $\begin{array}{l}\text { Exponential phase of growth } \uparrow \\
\text { Stationary phase of growth } \downarrow \\
\text { SAM } \uparrow \\
\text { Intracellular growth in } \\
\text { macrophages } \downarrow \\
\text { Intestinal lumen } \uparrow \\
\text { blood } \uparrow\end{array}$ & Virulence & $\begin{array}{l}\text { Loh et al., 2009; Mraheil } \\
\text { et al., } 2011\end{array}$ \\
\hline $\begin{array}{l}\text { Lysine } \\
\text { riboswitch } \\
\text { (LysRS) }\end{array}$ & 198 & Imo0798 & $\begin{array}{l}\text { Lysine } \uparrow \\
\text { Intracellular growth in } \\
\text { macrophages } \downarrow\end{array}$ & ND & $\begin{array}{l}\text { Toledo-Arana et al., 2009; } \\
\text { Mraheil et al., } 2011\end{array}$ \\
\hline $\begin{array}{l}\text { Vitamin } \mathrm{B}_{12} \\
\text { riboswitch of } \\
\text { AspocR }\end{array}$ & 230 & 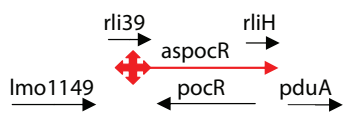 & $\begin{array}{l}\text { Intestinal lumen } \uparrow \\
\text { Propanediol } \uparrow\end{array}$ & $\begin{array}{l}\text { Propanediol utilization; } \\
\text { Vitamin } \mathrm{B}_{12} \text { biosynthesis }\end{array}$ & $\begin{array}{l}\text { Toledo-Arana et al., 2009; } \\
\text { Mellin et al., } 2013\end{array}$ \\
\hline $\begin{array}{l}\text { Vitamin } B_{12} \\
\text { riboswitch of } \\
\text { Rli55 }\end{array}$ & 200 & $\stackrel{\operatorname{Imo1170}}{\longrightarrow}$ & $\begin{array}{l}\text { Blood } \uparrow \\
\text { Intracellular growth in } \\
\text { macrophages } \downarrow\end{array}$ & $\begin{array}{l}\text { Ethanolamine utilization; } \\
\text { Virulence }\end{array}$ & $\begin{array}{l}\text { Toledo-Arana et al., 2009; } \\
\text { Mraheil et al., 2011; Mellin } \\
\text { et al., } 2014\end{array}$ \\
\hline $\begin{array}{l}\text { CspA } \\
\text { thermosensor }\end{array}$ & 101 & $\stackrel{\operatorname{Imo1363}}{\longrightarrow}$ & $26^{\circ} \mathrm{C}$ or below $\uparrow$ & Cold stress tolerance & $\begin{array}{l}\text { Schmid et al., 2009; } \\
\text { Ignatov et al., } 2020\end{array}$ \\
\hline \multicolumn{6}{|c|}{ regulatory $5^{\prime}$ UTR } \\
\hline hly & NA & $\stackrel{\text { plcA }}{\longleftarrow} \stackrel{\text { hly }}{\longrightarrow} \stackrel{\mathrm{mpl}}{\longrightarrow}$ & $\begin{array}{l}37^{\circ} \mathrm{C} \uparrow \\
\text { Infection } \uparrow\end{array}$ & Virulence & Peterson et al., 2020 \\
\hline \multicolumn{6}{|c|}{ regulatory $3^{\prime}$ UTR } \\
\hline hly & NA & $\longleftrightarrow$ plcA $\stackrel{\text { hly }}{\longrightarrow} \stackrel{\mathrm{mpl}}{\longrightarrow}$ & $\begin{array}{l}37^{\circ} \mathrm{C} \uparrow \\
\text { Infection } \uparrow\end{array}$ & Virulence & Ignatov et al., 2020 \\
\hline
\end{tabular}

${ }^{a}$ Arrows indicate the sense of the gene on the genome; data acc. to Toledo-Arana, modified; indicate localization of a riboswitch.

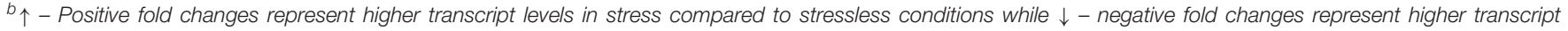

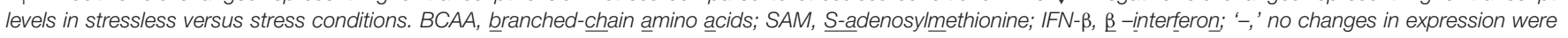
detected; ND, not determined; NA, not applicable.

from $l m o 2186$, $l m o 2185$, and $l m o 0484$, and for $l m o 0484$ it was confirmed that the LhrC-binding site overlaps with the AG-rich $\mathrm{SD}$ region of the mRNA. Furthermore, LhrC1-5 down-regulate the expression of $1 m o 0484$ at the posttranscriptional level in response to the cell wall-acting antibiotic cefuroxime through base pairing to the RBS, leading to inhibition of translation (dos Santos et al., 2018). While LhrC1-5 are known to interact with the chaperone Hfq, the interaction between LhrC and mRNAs has been shown so far to be Hfq-independent. A common feature of each LhrC family member is a structure that contains two stem loops (named stem loop A and terminator loop) joined by a single stranded stretch. Each LhrC family member contains two highly conserved UCCC motifs located in loop A and the single stranded stretch. LhrC1-5 contain an additional UCCC motif in the terminator loop. These motifs have been shown to be responsible for the interaction between these ncRNAs and their 

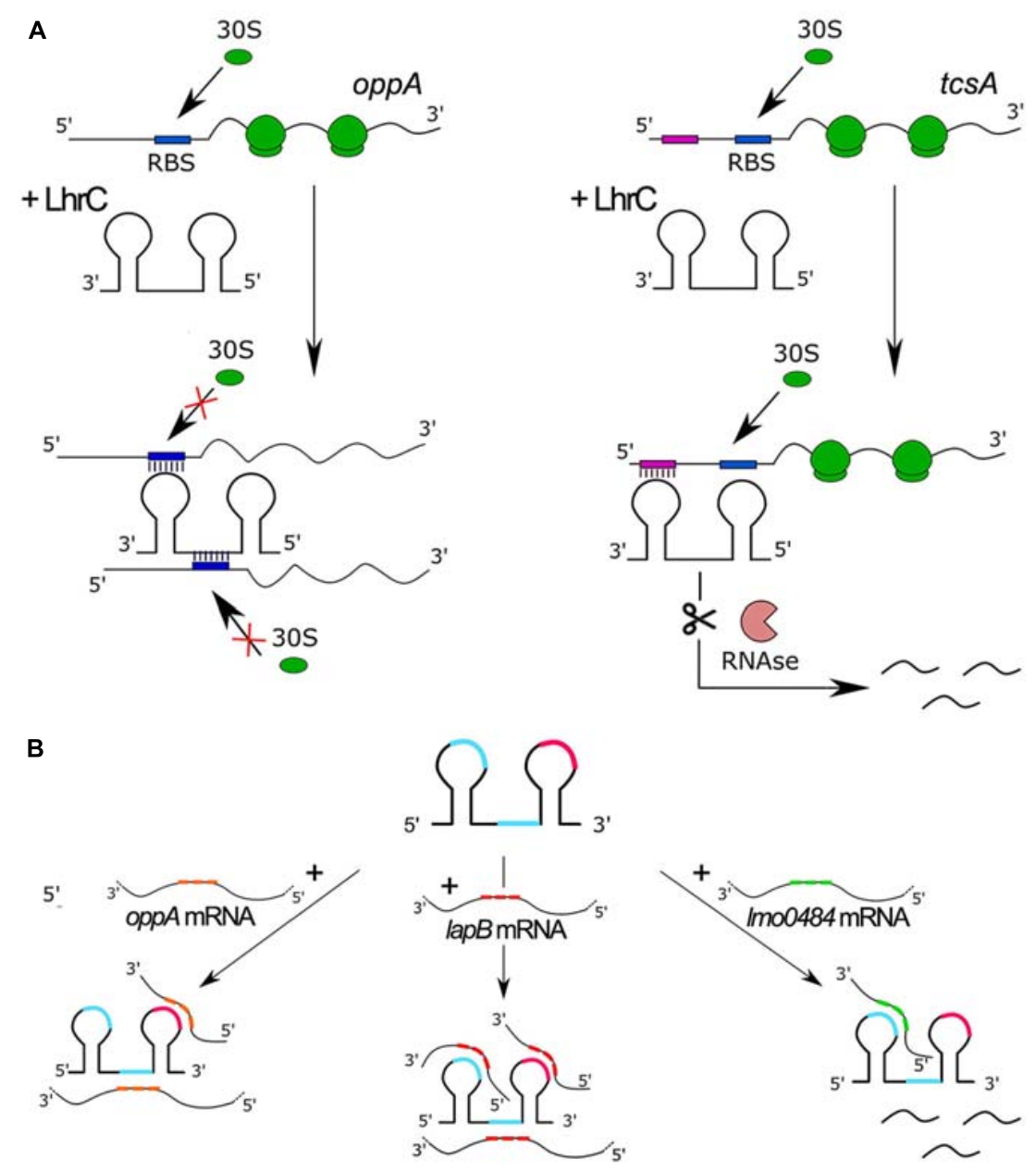

FIGURE 2 | Features and regulatory mechanisms of ncRNAs from the LhrC family. (A) Model of LhrC regulation of oppA (left) and tcsA (right). The LhrC ncRNAs repress oppA expression by directly base paring to the RBS, leading to ribosome occlusion and repression of translation. In contrast, the LhrC ncRNAs repress tcsA expression by base pairing to a sequence far upstream of the RBS leading to degradation of tcsA mRNA without directly affecting translation. (B) Model of LhrCs and LhrC-target mRNA interactions. Each LhrC molecule possesses two different sites containing a UCCC motif located in loop A and the single-stranded region (blue). LhrC1-5 have an additional UCCC motif in the terminator loop (pink). CU-rich sequences are capable of binding to the AG-rich SD region of target mRNAs oppA, lapB, and Imo0484. One LhrC molecule may bind three lapB mRNAs, two oppA mRNAs or one Imo0484 mRNA, and the target mRNAs show different binding preferences for the individual UCCC motifs.

target mRNA sequences. Despite general similarity, the structure of the stem loops of Rli22 and Rli33-1 is slightly different from the structure of LhrC1-5. Interestingly, LhrC uses a different number of its UCCC motifs when pairing with different partners (see Figure 2B). For example, all three motifs in LhrC4 are capable of binding lapB mRNA, two are required for binding oppA mRNA, whereas only one is sufficient for efficient binding of lmo0484 mRNA (Sievers et al., 2014, 2015; dos Santos et al., 2018). The unusually high number of binding sites of LhrC is considered to be a way of amplifying a weak input signal into a strong output response. Multiple binding sites may also accelerate the regulatory effect of LhrC, by binding multiple mRNAs at the same time. Additionally, different flanking regions adjacent to the UCCC motifs provide LhrC with a high degree of flexibility in terms of binding to SD regions of various target mRNAs.

\section{RliB}

RliB displays five repeats of 29 nt spaced by $35-36 \mathrm{nt}$, strikingly resembling CRISPR (Clustered Regularly Interspaced Short Palindromic Repeats) elements present in many prokaryotes and archaea (Mandin et al., 2007). RliB is conserved at the same genomic locus in L. monocytogenes strains and also in other Listeria species (Mandin et al., 2007; Sesto et al., 2014). The deletion of $r$ liB led to faster colonization of the livers of infected mice, indicating that $\mathrm{RliB}$ is involved in controlling virulence (Toledo-Arana et al., 2009; Table 1). A bioinformatic analysis was applied in an attempt to identify the targets of this ncRNA and this allowed prediction of three bicistronic transcripts as putative RliB targets, from which lmo2104-lmo2105, encoding the ferrous iron transport proteins FeoA and FeoB, respectively, was further analyzed (Mandin et al., 2007). The study revealed 
a weak complex formation ability between $\mathrm{RliB}$ and $1 m 02104$ and an increase of the lmo2104-lmo2105 mRNA levels in L. monocytogenes as a consequence of overexpression of RliB, suggesting that an interaction of RliB with lmo2104-lmo2105 mRNA may occur in vivo (Mandin et al., 2007). Further studies focused on the initially observed similarity of RliB to CRISPR elements and revealed that RliB is an atypical member of the CRISPR family, whose processing does not depend on cas (CRISPR-associated) genes (Sesto et al., 2014). Interestingly, an endogenously encoded polynucleotide phosphorylase (PNPase) with both $3^{\prime}-5^{\prime}$ exoribonuclease and $3^{\prime}$ polymerase activities, has been identified as the enzyme responsible for processing of RliB-CRISPR into a $280 \mathrm{nt}$ mature form. The PNPase-dependent processing of RliB-CRISPR is observed both in the cas-less L. monocytogenes strains and in those encoding a complete set of cas genes elsewhere in the genome. Functional studies revealed that RliB-CRISPR has DNA interference activity for which it requires the presence of both PNPase and the cas genes belonging to CRISPR-I (Sesto et al., 2014). These results indicate the involvement of RliB in the defense of L. monocytogenes against bacteriophage infection in strains carrying cas genes, however, the role of RliB in cas-less strains remains unknown. It is speculated that RliB-CRISPR's cas-independent activity might rely on RNA interference that could be involved in controlling the formation of viral particles and lysis of the bacterial cell, transcriptiondependent DNA targeting or gene expression silencing at the posttranscriptional level (Sesto et al., 2014). However, these hypotheses, as well as the discovery of the regulatory mechanism of RliB in L. monocytogenes virulence, require further research.

\section{Rlil}

The rliI gene is conserved in L. innocua and Listeria ivanovii species. The expression of rliI in L. monocytogenes does not change under conditions related to the infection process but it increases in the stationary phase of growth (Mandin et al., 2007; Toledo-Arana et al., 2009). Three putative bicistronic transcripts have been predicted as RliI targets, i.e., Imo2660-lmo2659 encoding a transketolase and a ribulose-phosphate epimerase, lmo1035-lmo1036 encoding a beta-glucoside transporter subunit of a PTS system and a beta-glucosidase, and lmo2124-lmo2123 encoding components of a maltodextrin ABC transporter system. In each case, pairing of RliI with the $3^{\prime}$ ends of the target bicistronic mRNAs is anticipated (Mandin et al., 2007; Table 1). Among the anticipated mRNAs targets, binding of RliI with the lmo1035-lmo1036 transcript has been examined and proven. Furthermore, it has been observed that overexpression of RliI in L. monocytogenes decreases the level of lmo1035lmo1036 mRNA, which suggests that RliI promotes the degradation of this transcript (Mandin et al., 2007). More recently, term-seq analysis, which maps the 3 -termini of RNA transcripts on a genome-wide scale, revealed that RliI is a putative conditional-terminator of the downstream gene lmo2760 encoding an ABC transporter ATP-binding protein. This observation strongly suggests the role of RliI as a cis regulator (Dar et al., 2016). While the predicted function of the RliI targets suggests that this ncRNA is involved in controlling sugar metabolism and transport, the physiological role of RliI remains unknown.

\section{SbrE (Rli47)}

The SbrE ncRNA is highly conserved among L. monocytogenes strains. In addition to L. monocytogenes, sbrE was also detected in the genomes of L. innocua and Listeria welshimeri (Mraheil et al., 2011). It was shown that SbrE affects the expression of the lmo0636-lmo0637 operon (Mujahid et al., 2012). The Lmo0636 protein is predicted to be a DNA binding protein of the RrF2 family and Lmo0637 was annotated as an UbiE/COQ5 family methyltransferase. Additionally, in a mutant lacking sbrE a diminished level of Lmo2094, which is a metal ion binding class II aldolase/adducin domain protein, was observed. Studies of a $s b r E$ deficient strain showed no significant effect of SbrE on growth in acid stress, salt stress, glucose-limiting conditions, or low temperature. Furthermore, the susceptibility of the sbrE mutant strain to infection with Listeria phages was comparable to the wild type strain (Mujahid et al., 2012). However, recent studies revealed that SbrE interacts with the SD region of the ilvA mRNA, which encodes threonine deaminase, an enzyme required for branched-chain amino acid biosynthesis (Marinho et al., 2019). Subsequent investigations revealed that in a mutant lacking the sbrE gene, both ilvA transcript levels and threonine deaminase activity were increased and the mutant also displayed a shorter growth lag in isoleucine-depleted growth media. These data indicate that SbrE acts to inhibit growth of L. monocytogenes under harsh conditions, through repression of isoleucine biosynthesis (Marinho et al., 2019). Furthermore, global transcriptional analyses revealed that SbrE is involved in modulation of amino acid metabolism and that the SbrE regulon largely overlaps with that of CodY, further establishing a possible role of Rli47 in the global regulation of metabolism during stress conditions (Marinho et al., 2019).

\section{Rli27}

Rli27 is exclusive for the genus Listeria, with no orthologs found in other bacteria. Rli27 is responsible for the posttranscriptional regulation of lmo0514; the interaction region for Rli27 is located in the $5^{\prime}$ UTR of the target mRNA. Lmo0514 is an internalin-like protein with LPXTG motif, which is required for survival of $L$. monocytogenes in plasma (Quereda et al., 2016). It was shown that the abundance of Lmo0514 increases during infection of eukaryotic cells. The lmo0514 gene was found to be transcribed from two promoters resulting in two mRNAs, containing a shorter and longer $5^{\prime}$ UTR sequence, respectively (Figure 3 ). The latter one, which contains the Rli27 interaction site, is detected exclusively in intracellular bacteria. Interaction between Rli27 and Imo0514 long $5^{\prime}$ UTR mRNA has no effect on the transcript level of Imo0514, but results in increased translation. These observations suggest that the regulation is based on altering the secondary structure of the $5^{\prime}$ UTR that in turn leads to increased accessibility of the SD sequence (Quereda et al., 2014) (see Figure 3). Notably, the intracellular-specific translation of an alternative transcript, controlled by Rli27, is the only example 


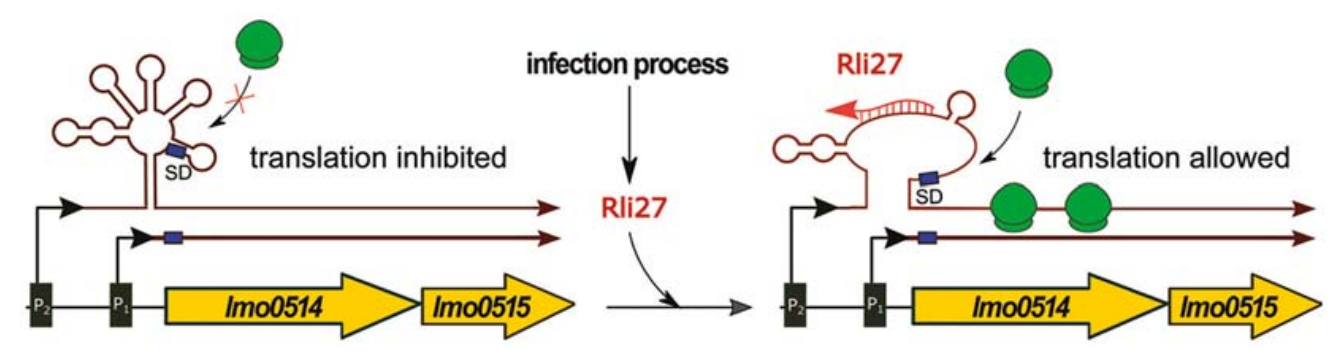

FIGURE 3 | Regulatory mechanism of Rli27. In conditions not related to infection, the expression of Imo0514-Imo0515 proceeds mainly from the constitutive P1 promoter as ribosomes cannot access the Shine-Dalgarno sequence (SD) within the long mRNA produced from the P2 promoter. During infection Rli27 is expressed and base-pairs with the 5' UTR of the long transcript arising from the P2 promoter. The interaction between Rli27 and 5' UTR of the long Imo0514-Imo0515 mRNA allows ribosome binding and translation to proceed.

described so far of positive regulation by trans ncRNAs in L. monocytogenes.

\section{Rli31}

While Rli31 is highly abundant and expressed in all growth phases of $L$. monocytogenes, its transcription increases significantly during the infection of macrophage cells. Deletion of rli31 results in decreased lysozyme resistance, decreased survival of L. monocytogenes in macrophages, and attenuation of virulence in insect and murine models of infection (Mraheil et al., 2011; Burke et al., 2014). Decreased mRNA levels of $p g d A$ and $p b p X$ (encoding peptidoglycan deacetylase and putative carboxypeptidase, respectively) were observed in the rli31 mutant strain. However, Rli31 does not show any sequence complementarity to $p g d A$ or $p b p X$ transcripts, suggesting that Rli31 regulates expression of these genes in an indirect way (Burke et al., 2014). Rli31 was also proposed to function as the transcriptional attenuator of $1 m o 0559$ encoding a $\mathrm{Mg}^{+} / \mathrm{Co}^{+}$ transporter, but this putative cis-regulation was not studied in detail (Dar et al., 2016). A further genetic screen for Rli31 target genes revealed that Rli31 binds the $5^{\prime}$ UTR of spoVG mRNA, as well as SpoVG protein (Table 1). However, despite its binding properties, Rli31 does not regulate SpoVG mRNA or protein abundance (Burke and Portnoy, 2016). Notably, SpoVG is a global regulator involved in lysozyme resistance, motility and virulence of L. monocytogenes and is itself able to bind various ncRNAs in vitro (Burke and Portnoy, 2016). Furthermore, inactivation of rli31 and spoVG results in an opposite effect on lysozyme resistance and virulence, suggesting the existence of an antagonistic regulatory relationship between them. The molecular mechanism of Rli31 regulation and its link to SpoVG definitely requires further investigation.

\section{Rli32}

Gene rli32 is highly conserved in L. monocytogenes. The expression of Rli32 is stable in different conditions, including the intestinal lumen and whole human blood, but increases during infection of macrophage cells (Toledo-Arana et al., 2009; Mraheil et al., 2011). It has been shown that expression of Rli32 strongly depends on the transcriptional regulator of virulence VirR (Grubaugh et al., 2018). Furthermore, Rli32 holds the ability to bind to protein SpoVG, but the biological significance of this interaction remains unknown (Burke and Portnoy, 2016). More recently, a secRNome analysis of RNAs secreted by $L$. monocytogenes led to identification of Rli32 among ncRNAs that are secreted into the host cytoplasm following infection with $L$. monocytogenes, with strong $\beta$-interferon (IFN$\beta$ ) inducing properties. The observed IFN- $\beta$ expression triggered by Rli32 depends mainly on the presence of RIG-I (retinoic acid inducible gene I), and it was postulated that Rli32 is a ligand recognized by the RIG-I receptor (Frantz et al., 2019). Deletion of rli32 results in decreased survival of $L$. monocytogenes in macrophages and increased resistance to the beta-lactam antibiotic cefuroxime. By contrast, the overexpression of Rli32 promotes intracellular bacterial growth and decreased resistance to cefuroxime. Additionally, L. monocytogenes overexpressing Rli32 is more resistant to $\mathrm{H}_{2} \mathrm{O}_{2}$ and exhibits increased catalase activity (Frantz et al., 2019). Comparative transcriptome analysis revealed that deletion of rli32 led to the downregulation of ncRNA Rli60 and genes lmo1627-lmo1633, corresponding to the complete tryptophan operon, while the overexpression of Rli32 resulted in elevated expression of ncRNAs LhrC1-4, lmo1958 and lmo1960 encoding ferrichrome ABC transporter permease components, and operon lmo2181-lmo2186 encoding heme-binding proteins $\mathrm{Hbp} 1$ and $\mathrm{Hbp} 2$, and components of a ferrichrome ABC transport system (Frantz et al., 2019). Especially intriguing seems the link between Rli32 and LhrC1-4, since inactivation of rli32 and $l h r C 1-4$ results in an opposite effect on cefuroxime resistance. The molecular regulatory mechanism of Rli32 and its link to LhrC1-4 requires further investigation.

\section{Rli38}

Rli38 is absent in non-pathogenic L. innocua and its expression is at least partially dependent on Sigma B (Toledo-Arana et al., 2009). Three putative mRNAs have been predicted as Rli38 targets, i.e., Imo1956 (fur), Imo0460, and lmo2752. Notably, two of these genes encode proteins with roles in virulence: the transcriptional repressor Fur corresponds to the global iron uptake regulator and Lmo0460 is a membrane associated lipoprotein belonging to internalin family proteins. While the details of the interaction of Rli38 with its putative mRNA targets remain unknown, a functional analysis has shown that deletion of 
the rli38 gene leads to attenuation of L. monocytogenes virulence in the murine model of infection, thus confirming the postulated importance of Rli38 in pathogenesis (Toledo-Arana et al., 2009).

\section{Rli50}

Rli50 was first reported to be $176 \mathrm{nt}$ in length (Toledo-Arana et al., 2009), but further studies revealed that the length of the Rli50 transcript is $306 \mathrm{nt}$ (Mraheil et al., 2011). Moreover, it partially overlaps with Rli112 encoded from the opposite strand (Table 1). Rli50 shares homology with another ncRNA - Rli28 that is encoded from the region between $1 \mathrm{mo} 0470$ and $1 m o 0471$ genes. Bioinformatic analysis showed that the chromosomal locus including rli28 (lmo0459-lmo0479) has a different GC-content, which together with the presence of a IS3 family transposase gene (lmo0464) in this region led to speculation that horizontal gene transfer might be involved in chromosomal spreading of these regulatory RNAs (Mraheil et al., 2011). The Rli50 transcript level was slightly higher in extracellular versus intracellular conditions, but noteworthily, Rli50 is one of the most highly transcribed ncRNAs in L. monocytogenes under intracellular conditions. Deletion of the rli50 gene resulted in decreased survival of L. monocytogenes in macrophage cells and led to attenuation of $L$. monocytogenes virulence in murine and insect models of infection. The attenuated virulence phenotype can be at least partially justified by the observed IFN- $\beta$ induction in cells transfected with Rli50, which suggests the involvement of Rli50 in modulating the immune response during infection (Frantz et al., 2019). In silico studies showed that both Rli50 and Rli28 could pair with the mRNA of $1 m o 0549$, which shows similarity to an internalin-like gene. In addition, Rli50 is predicted to bind other ncRNAs such as Rli44, which suggests the existence of a regulatory network based on interaction between ncRNAs (Toledo-Arana et al., 2009). However, these putative interactions require experimental confirmation.

\section{CIS REGULATORY ncRNAs}

\section{Rli53}

Initially, Rli53 was annotated as a conserved cis regulatory ncRNA located in the 5' UTR of $\operatorname{lmo0919}$ (Table 1). However, it has also been hypothesized that Rli53 might function as a riboswitch, with an open state when $L$. monocytogenes resides in the intestinal lumen and a closed state in blood (ToledoArana et al., 2009). Recent term-seq studies revealed that Rli53 forms two alternative RNA structures that terminate or antiterminate the transcription of the downstream lmo0919 gene, in response to the presence of the translation-inhibiting antibiotic lincomycin. In the absence of the antibiotic, transcription is terminated prematurely leading to the formation of a $207 \mathrm{nt}$ Rli53 transcript. However, in the presence of the antibiotic, termination of Rli53 in the 5' UTR of lmo0919 is diminished, leading to increased transcription of $l m o 0919$ encoding an ABC transporter providing resistance to lincomycin (Dar et al., 2016). The predicted structure of Rli53 displays a conserved antiantiterminator/antiterminator arrangement overlapping with a three-amino-acid ORF, which is translated in L. monocytogenes. Detailed functional studies revealed that the Rli53 regulatory mechanism relies on transcription attenuation mediated by lincomycin-inhibited ribosomes, which stall on the three-aminoacid ORF. This causes a shift of the riboregulator structure from a closed to an open state leading to induced expression of the fulllength $\operatorname{lmo0919}$ mRNA that provides resistance to lincomycin (Dar et al., 2016).

\section{Rli59}

Rli59 is a conserved cis regulatory ncRNA with a small ORF within its sequence (Toledo-Arana et al., 2009). Similar to Rli53, termination of Rli59 in the $5^{\prime}$ UTR of $1 m 01652$ is hampered by sub-lethal doses of translation-inhibiting antibiotics and leads to increased transcription of lmo1652 encoding an $\mathrm{ABC}$ transporter with unknown function. However, the physiological effect of this regulation remains unknown, and furthermore regulation in this case is more permissive since Rli59 responds to different translation inhibiting antibiotics including lincomycin, erythromycin and chloramphenicol (Dar et al., 2016). While details concerning Rli59 regulation are missing, it is postulated that similarly to Rli53, Rli59 would control the level of $l m o 1652$ transcription via a mechanism of translation-coupled ribosomemediated attenuation (Dar et al., 2016).

\section{Rli60}

Rli60 is encoded from the region upstream of $i l v D$, which is the first gene of the branched-chain amino acids (BCAA) biosynthesis operon ilv-leu (see Figure 4). Rli60 was predicted to function as a riboswitch with increased transcription in blood (Toledo-Arana et al., 2009) or as a ncRNA with a small ORF within its sequence (Mraheil et al., 2011). Other studies have suggested a role for Rli60 in stress adaptation, biofilm formation and virulence of L. monocytogenes, by a mechanism that is not known (Peng et al., 2016a,b). Recent studies revealed that rli60 is co-transcribed with $i l v D$ under BCAA limiting conditions, whereas under rich BCAA conditions a shorter transcript ( $200 \mathrm{nt})$ representing only Rli60 RNA is produced (Brenner et al., 2018; Figure 4). Of note, transcription of $i l v D$ depends solely on transcription of rli60 as $i l v D$ does not possess a promoter on its own, meaning that transcription of $i l v D$ is driven from the promoter located upstream of rli60. Detailed studies revealed that in low concentration of BCAA rli60 is transcribed, forming two alternative RNA structures that terminate or antiterminate the transcription of the downstream ilv-leu genes. Transcription attenuation is dictated by a 13 -amino-acid leader peptide rich in BCAA, which is translated ribosomally, implying that this mode of regulation corresponds to classical translationcoupled ribosome-mediated attenuation (Figure 4). Thus, Rli60 functions as a ribosome-mediated attenuator that regulates BCAA biosynthesis genes in cis and it is important for shutting down BCAA production even under BCAA depletion. This regulatory mechanism is crucial for virulence, as it ensures low level of the internal pools of BCAA, which is the signal for direct binding of the CodY regulator in the coding sequence of prfA. In turn, CodY activates the transcription of prfA and thereby stimulates the expression of virulence genes (Lobel et al., 2015; Brenner et al., 2018). Whether the 200 nt Rli60 ncRNA produced in BCAA rich condition functions as a trans acting regulator remains unknown. However, a recent study revealed 


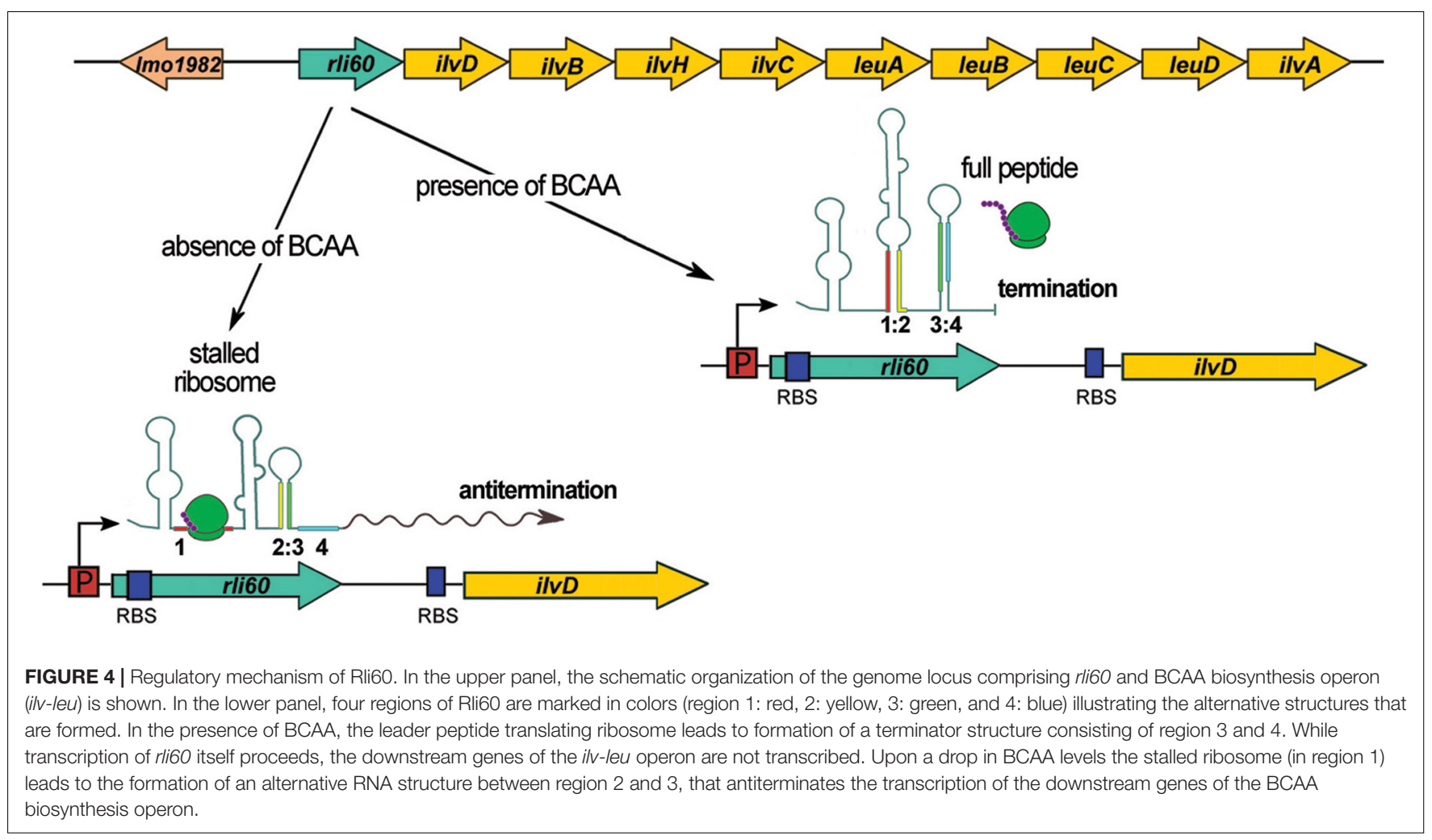

that transfection of eukaryotic cells with Rli60 triggers moderate IFN- $\beta$ induction (Frantz et al., 2019), suggesting that this ncRNA could have an additional role during infection that relies on modulating the immune response.

\section{lasRNAs (EXCLUDONS)}

Anti0677 is an example of a unique class of lasRNA transcripts called excludons. These lasRNAs contain the mRNA sequence of a gene and an exceptionally long $5^{\prime}$ or $3^{\prime}$ UTR. The UTR region overlaps other genes transcribed on the opposite strand, affecting their expression. The transcription of anti0677 originates on the opposite strand to the coding sequence of three genes of the flagellum operon: fliN, fliP, and fliQ and the distal part of the excludon contains the coding sequence of the $\operatorname{mog} R$ gene, which encodes a transcriptional repressor of flagellum genes (Table $\mathbf{1}$ and Figure 5). The $m o g R$ gene is transcribed from two promoters: transcription from the first, located just upstream of the start codon, generates a 1,200 nt transcript, whereas the second promoter is Sigma B dependent and drives transcription of a 2,900 nt Anti0677 excludon (Toledo-Arana et al., 2009). While the shorter $\operatorname{mog} R$ transcript is generated constitutively, anti0677 was observed to be highly expressed during the stationary phase of growth. The expression of anti0677 has a dual regulatory effect on the expression of the flagellum operon. First, it leads to higher transcription of $\operatorname{mog} R$, that in turn causes more efficient repression of transcription of the flagellum operon. Second,

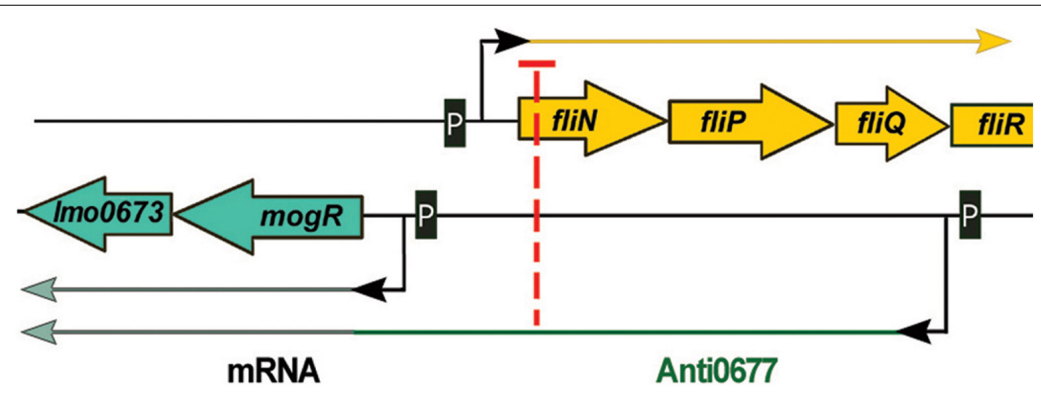

FIGURE 5 | Regulatory mechanism of Anti0677 (excludon). The transcription of anti0677 originates on the opposite strand to the coding sequence of three genes of the flagellum operon: fliN, fliP, and fliQ. The distal part of the excludon contains mogR, which encodes a transcriptional repressor of flagellum genes. The expression of anti0677 leads to a decrease in the amount of fliN, fliP, and fliQ transcript due to base pairing and processing, and results in higher transcription of $m o g R$, that in turn causes more efficient repression of transcription of the flagellum operon. 
it leads to a decrease in the amount of fliN, fliP, and fliQ transcript of flagellum operon due to base pairing and processing (Figure 5). Regarding a proposed action, the overexpression of anti0677 was shown to impair motility (Toledo-Arana et al., 2009). While Anti0677 was the first described excludon of L. monocytogenes, further transcriptomic studies revealed the existence of additional excludons in this bacterium, i.e., Anti0605, Anti1846, and Anti0424 (Wurtzel et al., 2012). The transcription of anti0605 inhibits expression of $l m o 0605$ encoding a MatEfamily multidrug efflux pump and simultaneously leads to expression of lmo0606 encoding a transcriptional regulator and two downstream genes (lmo0607 and lmo0608) encoding an ABC-type multidrug transport system. Transcription of anti1846 originates from the opposite strand relative to the coding sequence of 1 mo1846 encoding an efflux pump from the MatE family. The distal part of the excludon contains the coding sequence of the downstream lmo1845, Imo1844, and lmo1843 encoding xanthine-uracil permease, lipoprotein signal peptidase and ribosomal subunit synthase, respectively. It has been suggested that the anti1846 might lead to expression of the permease while expression of the efflux pump is repressed. In the case of anti0424, it has been shown that this excludon includes genes involved in importing and metabolizing fructose (lmo0425 and $l m o 0428$ ) whereas its $5^{\prime}$ UTR overlaps, in the antisense orientation, with a glucose-specific permease (lmo0424). While functional studies are missing for these excludons, it is suggested that they may represent a common mechanism of linking regulation of physically adjacent genes that have opposing functions (Wurtzel et al., 2012).

\section{RIBOSWITCHES AND THERMOSENSORS}

\section{PrfA Thermosensor}

The PrfA thermosensor is a $127 \mathrm{nt}$ riboregulator covering $115 \mathrm{nt}$ of the $5^{\prime}$ UTR and $12 \mathrm{nt}$ of the coding sequence of prfA, which encodes the master virulence regulator of $L$. monocytogenes. At environmental temperatures $\left(30^{\circ} \mathrm{C}\right.$ or below), the thermosensor element creates a stable hairpin structure which blocks the access of the ribosome to the SD sequence of prfA mRNA and therefore inhibits translation initiation. An increase of temperature to $37^{\circ} \mathrm{C}$ melts the stem-loop structure allowing the ribosome to access the $\mathrm{SD}$ sequence, resulting in translation of the $\operatorname{prfA}$ mRNA (Johansson et al., 2002; Table 1). The temperaturedependent control of prfA translation has a pivotal role in the virulence of $L$. monocytogenes as during infection of the host organism, the temperature rises to $37^{\circ} \mathrm{C}$, opens the stem-loop and unmasks the translation initiation site. Consequently, PrfA is produced, which results in the transcription of the PrfAdependent virulence genes.

\section{SreA Riboswitch}

The SreA riboswitch, termed for SAM (S-adenosyl-methionine) riboswitch elements, is located upstream from, and in orientation consistent with, lmo2419, lmo2418, and lmo2417 which encode proteins related to an $\mathrm{ABC}$-transporter system potentially involved in methionine uptake (Figure 6 and Table 1). Interestingly, the SreA riboswitch exhibits dual function. First, SreA acts as a riboswitch to regulate in cis the expression of the lmo2419-lmo2417 operon in a SAM-dependent manner. During growth in rich nutrient conditions, ensuring a high intracellular concentration of SAM, binding of the metabolite to the aptamer leads to premature termination of the operon transcription and formation of a truncated $229 \mathrm{nt}$ transcript representing SreA alone. Contrary, during growth at low nutrient conditions, reflecting the absence of SAM, a full-length polycistronic transcript of around $2800 \mathrm{nt}$ is produced (Loh et al., 2009). Therefore, in relation to regulation of the lmo2419-lmo2417 operon, SreA exhibits a default structure and mechanism of action like other SAM riboswitches. Notably, in addition to the in cis activity of SreA on transcriptional regulation, the riboswitch can give rise to an ncRNA with in trans regulatory properties. More specifically, it was shown that SreA can basepair, in trans, with the distal part of the $5^{\prime}$ UTR region of prfA mRNA. The interaction, which takes place approximately $80 \mathrm{nt}$ upstream of the SD site of $\operatorname{prfA}$, masks the SD sequence and impedes translation initiation (Loh et al., 2009). Thus, SreA acts as a dual riboregulator controlling the transcription of the downstream genes in cis, and furthermore, it acts in trans on distally located mRNAs, like prfA (Figure 6). Worth mentioning is that PrfA is a transcriptional activator of SreA expression. Therefore, SreA as a trans ncRNA constitutes part of a negative feedback loop on the expression of the main virulence regulator in L. monocytogenes. While the physiological effect of sreA inactivation was not examined, it is postulated that, according to the observed regulatory function on $\operatorname{prfA}$, it is involved in virulence control. In agreement with this, SreA ncRNA is transcribed in the intestinal lumen and in blood (Toledo-Arana et al., 2009), therefore giving rise to trans regulatory activity of SreA in these conditions related to pathogenesis. On the other hand, a decreased level of the SreA ncRNA was observed during infection of macrophages (Mraheil et al., 2011), which suggests that SreA-mediated modulation of prfA expression changes at different stages of the infection process. Additionally, inactivation of sreA led to an increased level of Imo2230 mRNA and decreased level of lmo0049 mRNA. However, the regulatory mechanism of SreA on these mRNAs was not examined and therefore remains unknown. Notably, in addition to SreA, L. monocytogenes has six additional putative SAM riboswitches, from which SreB was shown to prevent in trans translation of prfA as well (Loh et al., 2009). SreB was also shown to restore the expression of lmo2230, but not that of lmo0049 (Loh et al., 2009), suggesting that despite high similarity, the individual SAM riboswitches may differ in their ability to interact with mRNA targets.

\section{LysRS}

The LysRS riboswitch, encoded between $1 m o 0798$ and 1 mo0799, possesses a dual function. First, depending on the environmental conditions, the riboswitch acts as a terminator of transcription for the upstream gene lmo0799. The second regulatory mechanism of LysRS depends on the presence of lysine. Binding of the metabolite to the riboswitch leads to an alteration of its structure and results in transcription termination of the downstream 


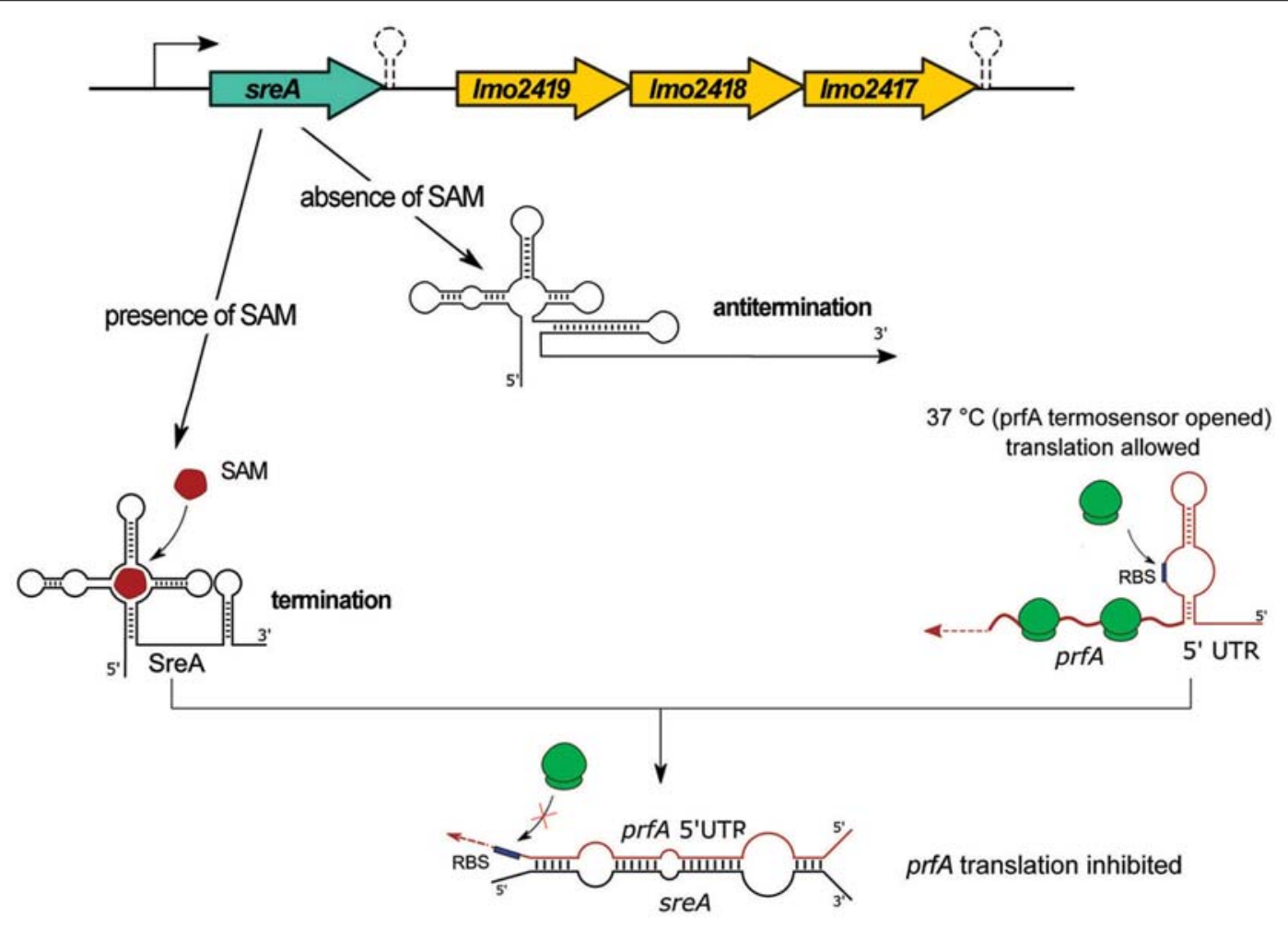

FIGURE 6 | Regulatory mechanisms of the SreA riboswitch. The upper panel illustrates the schematic organization of the genome locus comprising the SAM riboswitch SreA and the Imo2419-Imo2417 operon. In the absence of SAM the riboswitch element forms an antitermination structure that allows transcription of the downstream genes. Binding of SAM to the riboswitch alters its conformation, a terminator structure is formed, and downstream genes are not synthesized. The SreA small RNA, which is the product of a terminated riboswitch, base-pairs in trans with the $5^{\prime}$ UTR of prfA and blocks access of ribosomes to the SD sequence, which results in the inhibition of translation of prfA.

gene lmo0798 encoding a lysine transporter (Table 1). Notably, when lysine is absent, an anti-terminator structure is formed, which allows for transcription of the lysine transporter gene. Interestingly, in the absence of lysine a small transcript is generated, corresponding to LysRS alone (Toledo-Arana et al., 2009). The expression of lysRS proceeds from a Sigma B-dependent promoter, and its transcription increases in the presence of lysine and is strongly repressed during growth of L. monocytogenes in macrophages (Toledo-Arana et al., 2009; Mraheil et al., 2011). While the regulatory mechanism of LysRS is solved, its importance for L. monocytogenes physiology remains to be examined.

\section{Vitamin $B_{12}$ Riboswitch of AspocR}

A vitamin $\mathrm{B}_{12}$-dependent riboswitch is positioned between lmo1149 and $l m o 1150$, the latter encoding the transcriptional regulator PocR (Table 1). Initially, this riboswitch was annotated as ncRNA Rli39 and it was hypothesized to function as a riboswitch that terminates the transcription of 1 mo1149 (ToledoArana et al., 2009). However, further research revealed that the riboswitch is transcribed as part of, and controls transcription of, an antisense RNA to pocR (AspocR) in a vitamin $\mathrm{B}_{12}$-dependent manner (Mellin et al., 2013; Figure 7A). Notably, AspocR encompasses as well the previously identified $\mathrm{RliH}$ and taking into account that no TSS was identified for RliH, this ncRNA is anticipated to be a processed fragment of AspocR (Mandin et al., 2007; Wurtzel et al., 2012; Mellin et al., 2013). Binding of vitamin $\mathrm{B}_{12}$ to the riboswitch leads to premature termination of aspocR transcription and the arising of a truncated $230 \mathrm{nt}$ transcript. In the absence of vitamin $B_{12}$, a full length AspocR transcript of $1,400 \mathrm{nt}$ is produced, which inhibits pocR expression by an antisense mechanism (Figure 7A). PocR positively regulates expression of the $p d u$ genes involved in propanediol utilization, as well as the cob genes responsible for biosynthesis of vitamin $\mathrm{B}_{12}$, in response to the presence of propanediol. These regulatory functions of PocR are linked, as propanediol catabolism requires vitamin $B_{12}$ as a cofactor. The observed vitamin $B_{12}$ riboswitchdependent antisense regulation of $p o c R$ ensures that $p d u$ genes are expressed only when both the substrate and the cofactor are available. It is ensured by only partial repression of $p o c R$ by AspocR in response to the presence of propanediol but in unavailability of vitamin $\mathrm{B}_{12}$. In such conditions, the arising level of PocR is sufficient to activate expression of the cob genes and synthesis of $\mathrm{B}_{12}$ cofactor, while propanediol catabolism genes are repressed. Therefore, the vitamin $\mathrm{B}_{12}$ riboswitch and AspocR serve as fine-tuning riboregulators integrating signals on propanediol and vitamin $B_{12}$ availability (Mellin et al., 2013). While the regulatory mechanism of the riboswitch relies 


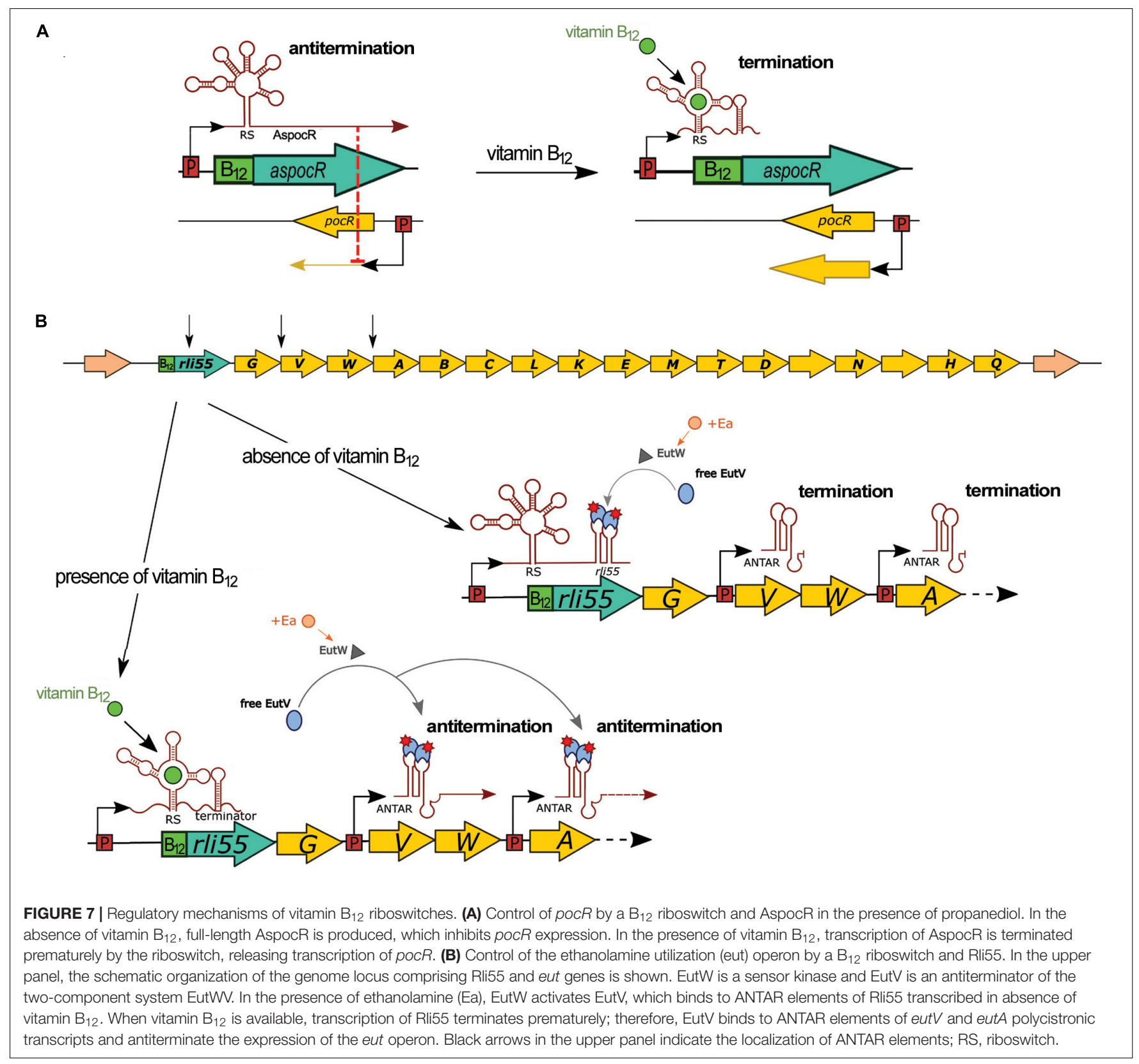

on modulation of transcription termination, the mechanistic details of AspocR regulation are elusive. AspocR inhibits pocR expression in trans, suggesting it acts through a direct interaction with pocR mRNA by a base-pairing mechanism rather than impeding the $p o c R$ transcription process. However, the possibility that AspocR may repress pocR expression at the level of transcription cannot be excluded. Furthermore, AspocR does not promote the degradation of pocR mRNA, which together with the higher level of PocR protein observed in the absence of AspocR in vitro suggests that AspocR interferes with translation initiation of pocR (Mellin et al., 2013). The expression of aspocR increases in the presence of propanediol and in the intestinal lumen, where propanediol is produced by commensal bacteria as a byproduct of the fermentation of rhamnose and fucose (Toledo-Arana et al., 2009; Mellin et al., 2013). While the effects of the vitamin $B_{12}$ riboswitch or full length AspocR on pathogenesis of L. monocytogenes have not been examined, it is anticipated that the riboregulator plays a role in this process as propanediol catabolism is important for the pathogenesis of many intestinal pathogens (Mellin et al., 2013).

\section{Vitamin B $_{\mathbf{1 2}}$ Riboswitch of Rli55}

The vitamin $\mathrm{B}_{12}$-dependent riboswitch is positioned upstream of Rli55 which is a ncRNA located in the close vicinity of the eut operon responsible for ethanolamine utilization (ToledoArana et al., 2009; Mellin et al., 2014; Figure 7B). Binding of vitamin $B_{12}$ to the riboswitch leads to premature termination of Rli55 transcription, resulting in a short, 200 nt transcript, 
while in the absence of vitamin $B_{12}$, a full-length transcript of around $450 \mathrm{nt}$ is produced (Mellin et al., 2014). Further analysis revealed that full-length Rli55 contains a structural motif similar to ANTAR (amiR and nasR transcriptional antiterminator regulator) elements. This motif corresponds to a binding site for the EutV antiterminator of a two-component system, EutVW, which is responsible for the upregulation of the eut operon. The eut genes require both ethanolamine and vitamin $\mathrm{B}_{12}$ to be transcribed. In the presence of ethanolamine alone, EutV is bound and sequestered by the ANTAR element of Rli55. Conversely, in the presence of ethanolamine and vitamin $B_{12}$, rli55 transcription terminates prematurely downstream from the riboswitch, and therefore it is transcribed without an ANTAR element. This transcript cannot bind EutV, and thus allows EutV to bind ANTAR elements of eut mRNAs and antiterminate eut expression (Figure 7B; Mellin et al., 2014). As enzymes of the ethanolamine utilization pathway use vitamin $\mathrm{B}_{12}$ as a cofactor, Rli55 prevents expression of the eut locus in the absence of $\mathrm{B}_{12}$, thereby ensuring that the eut genes are expressed only in the presence of both substrate and cofactor. Deletion of the vitamin $\mathrm{B}_{12}$ riboswitch of Rli55 led to significantly reduced virulence; in contrast, deletion of the whole rli55 sequence had no effect on virulence. Notably, Rli55 is the only ncRNA described so far in L. monocytogenes which regulates the expression of genes by the mechanism of the protein sequestration.

\section{CspA Thermosensor}

CspA thermosensor is a $101 \mathrm{nt}$ riboregulator located in the $5^{\prime}$ UTR of gene $\operatorname{csp} A$ encoding cold shock protein A (Table 1). At $37^{\circ} \mathrm{C}$, the $5^{\prime}$ UTR creates a stable hairpin structure in the region of the $\mathrm{SD}$ sequence, making it unavailable for ribosome binding and therefore preventing translation initiation of $\operatorname{csp} A$. A decrease of temperature to $30^{\circ} \mathrm{C}$ or below leads to the formation of a stable hairpin structure at the distal part of the $5^{\prime}$ UTR whereas the region containing the SD sequence becomes available for ribosome binding and thus translation of the cspA mRNA may proceed (Ignatov et al., 2020). The rearrangements of the thermosensor structure occur both in vivo and in vitro, indicating that a temperature change itself is sufficient to initiate conformational changes of the riboregulator. While the physiological role of thermosensor-driven control of $\operatorname{csp} A$ expression was not examined, it can be assumed that this regulatory mechanism is important for L. monocytogenes cold adaptation since CspA was shown to play an important role in cold stress tolerance (Schmid et al., 2009).

\section{REGULATORY 5' AND 3' UTRs}

Recent studies revealed non-canonical posttranscriptional regulation, in which the $5^{\prime}$ and $3^{\prime}$ UTRs of hly mRNA are involved (Ignatov et al., 2020; Peterson et al., 2020; Table 1). The hly gene encodes listeriolysin O (LLO); a secreted pore-forming cytolysin that is a key virulence factor of L. monocytogenes (Cossart, 2011). LLO promotes rupture of the host phagosome membrane and therefore enables bacterial escape into the cytoplasm, where bacteria replicate and undergo cell-tocell spreading. While the expression and activity of LLO is indispensable for L. monocytogenes virulence, it must be precisely regulated to ensure efficient escape of bacteria from a phagosome and to minimize cytotoxicity during growth inside the cytoplasm of infected cells. Recent work discovered that mRNA of hly forms an extensive secondary structure between the $5^{\prime}$ UTR comprising the RBS and a region encoding the PEST domain of LLO which is located near the N-terminus. The formation of this secondary mRNA structure is responsible for downregulation of LLO synthesis during bacterial growth (Peterson et al., 2020). Disruption of the interaction between the $5^{\prime}$ UTR-PEST sequence of hly mRNA did not change the level of $h l y$ mRNA but led to an increase of LLO. Further analysis revealed that this interaction is crucial for diminishing the cytotoxicity level during infection of host cells and therefore is important for L. monocytogenes virulence. Notably, $5^{\prime}$ UTR driven regulation of hly expression

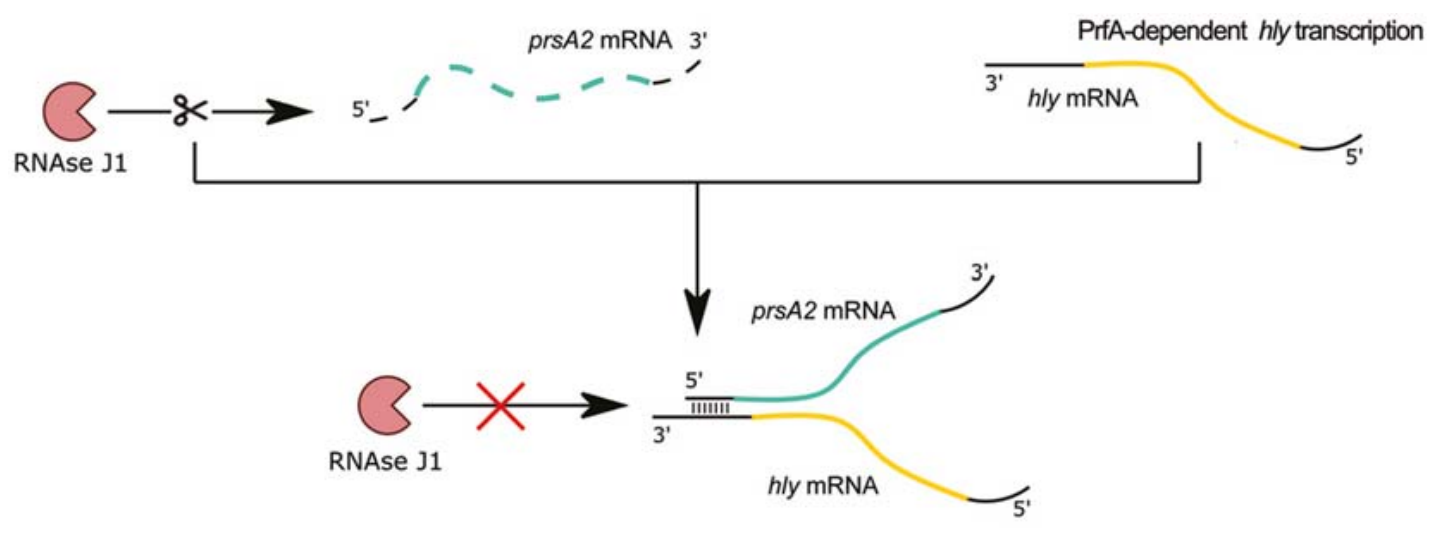

FIGURE 8 | Regulatory mechanism of $3^{\prime}$ UTR of hly on prsA2 mRNA. When the major virulence regulator PrfA is not active, transcription of the hly mRNA encoding the secreted virulence factor listeriolysin $\mathrm{O}$ does not proceed. In the absence of the hly transcript, the prsA2 transcript is degraded by exoribonuclease RNase $\mathrm{J} 1$. After PrfA activation, hly transcription proceeds. The $3^{\prime}$ UTR of the arising hly mRNA base pairs with the distal 5' end of the prsA2 mRNA and protects it from RNase J1-mediated degradation. 
is observed only for growing bacteria. However, more details concerning the dependency of this regulatory mechanism on growth phase remain to be elucidated.

The 3' UTR of hly mRNA is also involved in posttranscriptional gene regulation. In studies devoted to the discovery of RNA-RNA and RNA-protein interactions, prsA2 mRNA, encoding peptidyl-prolyl isomerase responsible for the folding of secreted proteins at the bacterial surface, was identified as the RNA target of posttranscriptional regulation by hly mRNA (Ignatov et al., 2020). Detailed studies revealed that the distal part of the $5^{\prime}$ UTR of prsA2 mRNA directly interacts in trans with the $3^{\prime}$ UTR of full length hly mRNA. Disruption of the interaction between $h l y$ and prsA 2 mRNAs led to a reduction of prsA2 mRNA level and protein abundance of PrsA2 but did not change hly mRNA level or the amount of LLO. The hly-prsA2 interaction does not influence ribosome binding to the SD sequence of prsA2 mRNA, but instead affects the stability of prsA2 mRNA. Further analysis revealed that interaction with hly mRNA protects prsA2 mRNA from degradation by RNase J1 (Figure 8), and that the $h l y$-prsA2 interaction is important for L. monocytogenes virulence (Ignatov et al., 2020). Of note, the PrsA2 surface chaperone was shown to promote secretion and stability of LLO (Zemansky et al., 2009), therefore hly-driven regulation of prs $A 2$ constitutes a posttranscriptional mechanism ensuring efficient secretion and activity of the regulator. Notably, the $h l y$-prsA2 interaction is the first described riboregulatory function of a $3^{\prime}$ UTR in L. monocytogenes.

\section{CONCLUDING REMARKS}

The transcriptomic studies of recent years revealed the expression of a huge number of ncRNAs in L. monocytogenes. However, the biological functions and regulatory mechanisms of most ncRNAs remain unknown. Despite this fragmentary picture of the regulatory properties of the ncRNAs, recent research on RNA-mediated regulation in $L$. monocytogenes clearly points to ncRNAs being crucial contributors to virulence and stress adaptation. Strikingly, the vast majority of regulatory RNAs studied thus far are important for virulence. Moreover, through their regulatory functions at various stages of pathogenesis, these elements ensure successful infection by L. monocytogenes. In the intestinal lumen, effective growth of bacteria is ensured by vitamin $B_{12}$ riboswitch-driven regulation (Mellin et al., 2014). In the blood, ncRNAs like the LhrCs and Rli27 contribute to resistance to heme toxicity and promote dissemination to deep lying organs (Quereda et al., 2016; dos Santos et al., 2018). Finally, in the intracellular phase of infection, efficient phagosome escape and low cytotoxicity inside the cytoplasm is ensured by riboregulatory elements involved in the control of LLO activity (Ignatov et al., 2020; Peterson et al., 2020). Importantly, multiple ncRNAs are known to regulate genes encoding cell envelope-associated proteins with virulence functions, such as $\operatorname{lap} B, \operatorname{tcs} A, h b p 1, h b p 2$, and Imo0514 (Sievers et al., 2014; Quereda et al., 2014; Sievers et al., 2015; dos Santos et al., 2018; Ross et al., 2019). Furthermore, ncRNAs involved in regulation of amino acid biosynthesis genes, such as ilvA and $i l v D$, have been found to affect virulence (Brenner et al., 2018; Marinho et al., 2019). These findings indicate that riboregulators play important roles during infection by controlling sensu stricto virulence factors and by modulating the expression of genes involved in immune evasion, iron acquisition, and general metabolism. While the significance of iron transport and metabolism in the pathogenesis of L. monocytogenes is well known (Lechowicz and Krawczyk-Balska, 2015), recent research also points to a link between amino acid availability and virulence, as exemplified by increased virulence gene expression in response to a decrease in BCAA availability (Lobel et al., 2015). Therefore, adequate adjustments of different metabolic pathways is clearly important for establishing a successful infection, and ncRNAs appear to play important roles in these regulatory processes. Regulatory links between different metabolic pathways and the virulence program of $L$. monocytogenes can be achieved due to the versatility of ncRNAs. For example, the LhrC ncRNAs control the level of proteins belonging to different functional categories, such as amino acid and peptide transport, iron transport and metabolism, and surface proteins involved in virulence (Sievers et al., 2014; Sievers et al., 2015; dos Santos et al., 2018). Furthermore, SAM-dependent downregulation of prfA by SreA during growth in rich nutrient conditions also illustrates the important role of riboregulatory elements in the cross-coordination of virulence with metabolic pathways, and furthermore illustrates the complexity of riboregulation in this pathogen (Loh et al., 2009). This complexity is clearly manifested by the ability of regulatory RNAs to integrate complex metabolic stimuli, such as availability of different carbon sources and cofactors, into regulatory networks as exemplified by AspocR and Rli55 vitamin $\mathrm{B}_{12}$ riboswitches (Mellin et al., 2013, 2014). Presently, the complexity of regulation involving ncRNAs might be underestimated, as evidenced by the recently described Rli32-dependent changes in LhrC1-4 and Rli60 expression, which strongly suggests the existence of a regulatory network comprising multiple ncRNAs (Frantz et al., 2019). Intriguingly, multiple ncRNAs have been recently reported to modulate the innate immune response through interaction with host sensor RIG-I, suggesting that riboregulatory elements act to link and fine-tune the expression of both bacterial and host genes as a part of $L$. monocytogenes' virulence strategies (Frantz et al., 2019).

Noteworthily, studies of riboregulation in L. monocytogenes have led to the definition of new concepts in prokaryotic gene regulation, such as the excludon, and disclosure of the versatility of riboswitches (Loh et al., 2009; Toledo-Arana et al., 2009; Wurtzel et al., 2012). However, further studies are required to explain the molecular basis and physiological role of unexplored post-transcriptional regulators. Such studies represent a demanding task, considering that riboregulators often represent fine-tuning, subtle modulation instead of all-ornothing regulation. Notably, the regulatory function of most $5^{\prime}$ and $3^{\prime}$ UTRs is waiting to be revealed. Similarly, most excludons and their roles in adaptation to environmental conditions are still unknown. With a few exceptions, very little is known about RNA chaperones, such as Hfq, and other RNA binding proteins 
in L. monocytogenes (Jorgensen et al., 2020). So far, LhrA is the only example of an Hfq-dependent regulatory ncRNA in L. monocytogenes. Clearly, additional RNA binding proteins and their RNA partners remain to be uncovered in this bacterium. Furthermore, RNA-mediated regulation is triggered in response to changing environmental conditions, therefore the exploration of riboregulation demands linking to - and understanding of the influence of specific environmental cues. Finally, an emerging theme in the field of riboregulation is the role of bacterial RNAs as virulence effectors modulating the expression of host genes during infection. In L. monocytogenes, the role of riboregulators in pathogen-host interactions most likely will continue being at the center of attention in the coming years.

\section{REFERENCES}

Anast, J. M., and Schmitz-Esser, S. (2020). The transcriptome of Listeria monocytogenes during co-cultivation with cheese rind bacteria suggests adaptation by induction of ethanolamine and 1, 2-propanediol catabolism pathway genes. PLoS One 15:e0233945. doi: 10.1371/journal.pone.0233945

Behrens, S., Widder, S., Mannala, G. K., Qing, X., Madhugiri, R., Kefer, N., et al. (2014). Ultra deep sequencing of Listeria monocytogenes sRNA transcriptome revealed new antisense RNAs. PLoS One 9:e83979. doi: 10.1371/journal.pone. 0083979

Brenner, M., Lobel, L., Borovok, I., Sigal, N., and Herskovits, A. A. (2018). Controlled branched-chain amino acids auxotrophy in Listeria monocytogenes allows isoleucine to serve as a host signal and virulence effector. PLoS Genet. 14:e1007283. doi: 10.1371/journal.pgen.1007283

Burke, T. P., and Portnoy, D. A. (2016). SpoVG is a conserved RNA-binding protein that regulates Listeria monocytogenes lysozyme resistance, virulence, and swarming motility. mBio 7:e00240. doi: 10.1128/mBio.00240-16

Burke, T. P., Loukitcheva, A., Zemansky, J., Wheeler, R., Boneca, I. G., and Portnoy, D. A. (2014). Listeria monocytogenes is resistant to lysozyme through the regulation, not the acquisition, of cell wall-modifying enzymes. J. Bacteriol. 196, 3756-3767. doi: 10.1128/JB.02053-14

Christiansen, J. K., Nielsen, J. S., Ebersbach, T., Valentin-Hansen, P., SøgaardAndersen, L., and Kallipolitis, B. H. (2006). Identification of small Hfq-binding RNAs in Listeria monocytogenes. RNA 12, 1383-1396. doi: 10.1261/rna.49706

Cossart, P. (2011). Illuminating the landscape of host-pathogen interactions with the bacterium Listeria monocytogenes. Proc. Natl. Acad. Sci. U.S.A. 108, 1948419491. doi: 10.1073/pnas.1112371108

Cotter, P. D., Emerson, N., Gahan, C. G. M., and Hill, C. (1999). Identification and disruption of lisRK, a genetic locus encoding a two-component signal transduction system involved in stress tolerance and virulence in Listeria monocytogenes. J. Bacteriol. 181, 6840-6843.

Dar, D., Shamir, M., Mellin, J. R., Koutero, M., Stern-Ginossar, N., Cossart, P., et al. (2016). Term-seq reveals abundant ribo-regulation of antibiotics resistance in bacteria. Science 352:aad9822. doi: 10.1126/science.aad9822

Dorey, A., Marinho, C., Piveteau, P., and O’Byrne, C. (2019). Role and regulation of the stress activated sigma factor sigma $\mathrm{B}(\sigma \mathrm{B})$ in the saprophytic and hostassociated life stages of Listeria monocytogenes. Adv. Appl. Microbiol. 106, 1-48. doi: 10.1016/bs.aambs.2018.11.001

dos Santos, P. T., Menendez-Gil, P., Sabharwal, D., Christensen, J.-H., Brunhede, M. Z., Lillebæk, E. M. S., et al. (2018). The small regulatory RNAs LhrC1-5 contribute to the response of Listeria monocytogenes to heme toxicity. Front. Microbiol. 9:599. doi: 10.3389/fmicb.2018.00599

Ferreira, V., Wiedmann, M., Teixeira, P., and Stasiewicz, M. J. (2014). Listeria monocytogenes persistence in food-associated environments: epidemiology, strain characteristics, and implications for public health. J. Food Prot. 77, 150-170. doi: 10.4315/0362-028X.JFP-13-150

Frantz, R., Teubner, L., Schultze, T., La Pietra, L., Müller, C., Gwozdzinski, K., et al. (2019). The secRNome of Listeria monocytogenes harbors small noncoding RNAs that are potent inducers of Beta interferon. mBio 10:e01223-19. doi: 10.1128/mBio.01223-19

\section{AUTHOR CONTRIBUTIONS}

$\mathrm{AK}-\mathrm{B}$ and $\mathrm{BK}$ contributed to conception and design of the manuscript. AK-B wrote the first draft of the manuscript. AK-B, $\mathrm{M} \ell$, and $\mathrm{MB}$ wrote sections of the manuscript. KS prepared figures. All authors contributed to manuscript revision, read, and approved the submitted version.

\section{FUNDING}

This work was supported by a grant no. 2015/18/E/NZ6/00643 from the National Science Center, Poland.

Grubaugh, D., Regeimbal, J. M., Ghosh, P., Zhou, Y., Lauer, P., Dubensky, T. W., et al. (2018). The VirAB ABC transporter is required for VirR regulation of Listeria monocytogenes virulence and resistance to nisin. Infect. Immun. 86, e00901-17. doi: 10.1128/IAI.00901-17

Ignatov, D., Vaitkevicius, K., Durand, S., Cahoon, L., Sandberg, S. S., Liu, X., et al. (2020). An mRNA-mRNA interaction couples expression of a virulence factor and its chaperone in Listeria monocytogenes. Cell Rep. 30, 4027-4040.e7. doi: 10.1016/j.celrep.2020.03.006

Johansson, J., Mandin, P., Renzoni, A., Chiaruttini, C., Springer, M., and Cossart, P. (2002). An RNA thermosensor controls expression of virulence genes in Listeria monocytogenes. Cell 110, 551-561. doi: 10.1016/s0092-8674(02)00905-4

Jorgensen, M. G., Pettersen, J. S., and Kallipolitis, B. H. (2020). sRNA-mediated control in bacteria: an increasing diversity of regulatory mechanisms. Biochim. Biophys. Acta Gene Regul. Mech. 1863:194504. doi: 10.1016/j.bbagrm.2020. 194504

Kallipolitis, B. H., Ingmer, H., Gahan, C. G., Hill, C., and Søgaard-Andersen, L. (2003). CesRK, a two-component signal transduction system in Listeria monocytogenes, responds to the presence of cell wall-acting antibiotics and affects beta-lactam resistance. Antimicrob. Agents Chemother. 47, 3421-3429. doi: 10.1128/aac.47.11.3421-3429.2003

Lebreton, A., and Cossart, P. (2017). RNA- and protein-mediated control of Listeria monocytogenes virulence gene expression. RNA Biol. 14, 460-470. doi: 10.1080/ 15476286.2016.1189069

Lechowicz, J., and Krawczyk-Balska, A. (2015). An update on the transport and metabolism of iron in Listeria monocytogenes: the role of proteins involved in pathogenicity. Biometals 28, 587-603. doi: 10.1007/s10534-015-9849-5

Liu, D., Lawrence, M. L., Ainsworth, A. J., and Austin, F. W. (2007). Toward an improved laboratory definition of Listeria monocytogenes virulence. Int. J. Food Microbiol. 118, 101-115. doi: 10.1016/j.ijfoodmicro.2007.07.045

Lobel, L., Sigal, N., Borovok, I., Belitsky, B. R., Sonenshein, A. L., and Herskovits, A. A. (2015). The metabolic regulator CodY links Listeria monocytogenes metabolism to virulence by directly activating the virulence regulatory gene prfA. Mol. Microbiol. 95, 624-644. doi: 10.1111/mmi.12890

Loh, E., Dussurget, O., Gripenland, J., Vaitkevicius, K., Tiensuu, T., Mandin, P., et al. (2009). A trans-acting riboswitch controls expression of the virulence regulator PrfA in Listeria monocytogenes. Cell 139, 770-779. doi: 10.1016/j.cell. 2009.08.046

Mandin, P., Fsihi, H., Dussurget, O., Vergassola, M., Milohanic, E., Toledo-Arana, A., et al. (2005). VirR, a response regulator critical for Listeria monocytogenes virulence. Mol. Microbiol. 57, 1367-1380. doi: 10.1111/j.1365-2958.2005. 04776.x

Mandin, P., Repoila, F., Vergassola, M., Geissmann, T., and Cossart, P. (2007). Identification of new noncoding RNAs in Listeria monocytogenes and prediction of mRNA targets. Nucleic Acids Res. 35, 962-974. doi: 10.1093/nar/ gkl1096

Marinho, C. M., Dos Santos, P. T., Kallipolitis, B. H., Johansson, J., Ignatov, D., Guerreiro, D. N., et al. (2019). The $\sigma$ B-dependent regulatory sRNA Rli47 represses isoleucine biosynthesis in Listeria monocytogenes through a direct interaction with the ilvA transcript. RNA Biol. 16, 1424-1437. doi: 10.1080/ 15476286.2019.1632776 
McLauchlin, J., Mitchell, R. T., Smerdon, W. J., and Jewell, K. (2004). Listeria monocytogenes and listeriosis: a review of hazard characterisation for use in microbiological risk assessment of foods. Int. J. Food Microbiol. 92, 15-33. doi: 10.1016/S0168-1605(03)00326-X

Mellin, J. R., Koutero, M., Dar, D., Nahori, M.-A., Sorek, R., and Cossart, P. (2014). Riboswitches. Sequestration of a two-component response regulator by a riboswitch-regulated noncoding RNA. Science 345, 940-943. doi: 10.1126/ science. 1255083

Mellin, J. R., Tiensuu, T., Bécavin, C., Gouin, E., Johansson, J., and Cossart, P. (2013). A riboswitch-regulated antisense RNA in Listeria monocytogenes. Proc. Natl. Acad. Sci. U.S.A. 110, 13132-13137. doi: 10.1073/pnas. 1304795110

Mollerup, M. S., Ross, J. A., Helfer, A.-C., Meistrup, K., Romby, P., and Kallipolitis, B. H. (2016). Two novel members of the LhrC family of small RNAs in Listeria monocytogenes with overlapping regulatory functions but distinctive expression profiles. RNA Biol. 13, 895-915. doi: 10.1080/15476286.2016.1208332

Mraheil, M. A., Billion, A., Mohamed, W., Mukherjee, K., Kuenne, C., Pischimarov, J., et al. (2011). The intracellular sRNA transcriptome of Listeria monocytogenes during growth in macrophages. Nucleic Acids Res. 39, 4235-4248. doi: 10.1093/ nar/gkr033

Mujahid, S., Bergholz, T. M., Oliver, H. F., Boor, K. J., and Wiedmann, M. (2012). Exploration of the role of the non-coding RNA SbrE in L. monocytogenes stress response. Int. J. Mol. Sci. 14, 378-393. doi: 10.3390/ijms14010378

Nielsen, J. S., Larsen, M. H., Lillebæk, E. M. S., Bergholz, T. M., Christiansen, M. H. G., Boor, K. J., et al. (2011). A small RNA controls expression of the chitinase ChiA in Listeria monocytogenes. PLoS One 6:e19019. doi: 10.1371/ journal.pone.0019019

Nielsen, J. S., Lei, L. K., Ebersbach, T., Olsen, A. S., Klitgaard, J. K., ValentinHansen, P., et al. (2010). Defining a role for Hfq in Gram-positive bacteria: evidence for Hfq-dependent antisense regulation in Listeria monocytogenes. Nucleic Acids Res. 38, 907-919. doi: 10.1093/nar/gkp1081

Nielsen, J. S., Olsen, A. S., Bonde, M., Valentin-Hansen, P., and Kallipolitis, B. H. (2008). Identification of a $\sigma \mathrm{B}$-dependent small noncoding RNA in Listeria monocytogenes. J. Bacteriol. 190, 6264-6270. doi: 10.1128/JB.00740-08

Oliver, H. F., Orsi, R. H., Ponnala, L., Keich, U., Wang, W., Sun, Q., et al. (2009). Deep RNA sequencing of $L$. monocytogenes reveals overlapping and extensive stationary phase and sigma B-dependent transcriptomes, including multiple highly transcribed noncoding RNAs. BMC Genomics 10:641. doi: 10.1186/14712164-10-641

Peng, Y.-L., Meng, Q.-L., Qiao, J., Xie, K., Chen, C., Liu, T.-L., et al. (2016a). The regulatory roles of ncRNA Rli60 in adaptability of Listeria monocytogenes to environmental stress and biofilm formation. Curr. Microbiol. 73, 77-83. doi: 10.1007/s00284-016-1028-6

Peng, Y.-L., Meng, Q.-L., Qiao, J., Xie, K., Chen, C., Liu, T.-L., et al. (2016b). The roles of noncoding RNA Rli60 in regulating the virulence of Listeria monocytogenes. J. Microbiol. Immunol. Infect. 49, 502-508. doi: 10.1016/j.jmii. 2014.08.017

Peterson, B. N., Portman, J. L., Feng, Y., Wang, J., and Portnoy, D. A. (2020). Secondary structure of the mRNA encoding listeriolysin $O$ is essential to establish the replicative niche of L. monocytogenes. Proc. Natl. Acad. Sci. U.S.A. 117, 23774-23781. doi: 10.1073/pnas.2004129117

Quereda, J. J., García-Del Portillo, F., and Pucciarelli, M. G. (2016). Listeria monocytogenes remodels the cell surface in the blood-stage. Environ. Microbiol. Rep. 8, 641-648. doi: 10.1111/1758-2229.12416

Quereda, J. J., Ortega, ÁD., Pucciarelli, M. G., and García-del Portillo, F. (2014). The Listeria small RNA Rli27 regulates a cell wall protein inside eukaryotic cells by targeting a long 5'-UTR variant. PLoS Genet. 10:e1004765. doi: 10.1371/ journal.pgen. 1004765

Reniere, M. L., Whiteley, A. T., and Portnoy, D. A. (2016). An in vivo selection identifies Listeria monocytogenes genes required to sense the intracellular environment and activate virulence factor expression. PLoS Pathog. 12:e1005741. doi: 10.1371/journal.ppat.1005741
Renzoni, A., Cossart, P., and Dramsi, S. (1999). PrfA, the transcriptional activator of virulence genes, is upregulated during interaction of Listeria monocytogenes with mammalian cells and in eukaryotic cell extracts. Mol. Microbiol. 34, 552-561. doi: 10.1046/j.1365-2958.1999.01621.x

Ross, J. A., Thorsing, M., Lillebæk, E. M. S., Teixeira Dos Santos, P., and Kallipolitis, B. H. (2019). The LhrCsRNAs control expression of T cell-stimulating antigen TcsA in Listeria monocytogenes by decreasing tcsA mRNA stability. RNA Biol. 16, 270-281. doi: 10.1080/15476286.2019.1572423

Schmid, B., Klumpp, J., Raimann, E., Loessner, M. J., Stephan, R., and Tasara, T. (2009). Role of cold shock proteins in growth of Listeria monocytogenes under cold and osmotic stress conditions. Appl. Environ. Microbiol. 75, 1621-1627. doi: 10.1128/AEM.02154-08

Schultze, T., Izar, B., Qing, X., Mannala, G. K., and Hain, T. (2014). Current status of antisense RNA-mediated gene regulation in Listeria monocytogenes. Front. Cell Infect. Microbiol. 4:135. doi: 10.3389/fcimb.2014.00135

Sesto, N., Touchon, M., Andrade, J. M., Kondo, J., Rocha, E. P. C., Arraiano, C. M., et al. (2014). A PNPase dependent CRISPR system in Listeria. PLoS Genet. 10:e1004065. doi: 10.1371/journal.pgen.1004065

Sievers, S., Lund, A., Menendez-Gil, P., Nielsen, A., Storm Mollerup, M., Lambert Nielsen, S., et al. (2015). The multicopy sRNA LhrC controls expression of the oligopeptide-binding protein OppA in Listeria monocytogenes. RNA Biol. 12, 985-997. doi: 10.1080/15476286.2015.1071011

Sievers, S., SternkopfLillebæk, E. M., Jacobsen, K., Lund, A., Mollerup, M. S., Nielsen, P. K., et al. (2014). A multicopy sRNA of Listeria monocytogenes regulates expression of the virulence adhesinLapB. Nucleic Acids Res. 42, 93839398. doi: 10.1093/nar/gku630

Storz, G., Vogel, J., and Wassarman, K. M. (2011). Regulation by small RNAs in bacteria: expanding frontiers. Mol. Cell 43, 880-891. doi: 10.1016/j.molcel.2011. 08.022

Toledo-Arana, A., Dussurget, O., Nikitas, G., Sesto, N., Guet-Revillet, H., Balestrino, D., et al. (2009). The Listeria transcriptional landscape from saprophytism to virulence. Nature 459, 950-956. doi: 10.1038/nature0 8080

Waters, L. S., and Storz, G. (2009). Regulatory RNAs in bacteria. Cell 136, 615-628. doi: 10.1016/j.cell.2009.01.043

Wehner, S., Mannala, G. K., Qing, X., Madhugiri, R., Chakraborty, T., Mraheil, M. A., et al. (2014). Detection of very long antisense transcripts by whole transcriptome RNA-Seq analysis of Listeria monocytogenes by semiconductor sequencing technology. PLoS One 9:e108639. doi: 10.1371/journal.pone. 0108639

Wurtzel, O., Sesto, N., Mellin, J. R., Karunker, I., Edelheit, S., Bécavin, C., et al. (2012). Comparative transcriptomics of pathogenic and nonpathogenic Listeria species. Mol. Syst. Biol. 8:583. doi: 10.1038/msb.2 012.11

Zemansky, J., Kline, B. C., Woodward, J. J., Leber, J. H., Marquis, H., and Portnoy, D. A. (2009). Development of a mariner-based transposon and identification of Listeria monocytogenes determinants, including the peptidyl-prolyl isomerase PrsA2, that contribute to its hemolytic phenotype. J. Bacteriol. 191, 3950-3964. doi: 10.1128/JB.00016-09

Conflict of Interest: The authors declare that the research was conducted in the absence of any commercial or financial relationships that could be construed as a potential conflict of interest.

Copyright (C) 2021 Krawczyk-Balska, Ladziak, Burmistrz, Ścibek and Kallipolitis. This is an open-access article distributed under the terms of the Creative Commons Attribution License (CC BY). The use, distribution or reproduction in other forums is permitted, provided the original author(s) and the copyright owner(s) are credited and that the original publication in this journal is cited, in accordance with accepted academic practice. No use, distribution or reproduction is permitted which does not comply with these terms. 